\title{
Caracterización genética del puma andino boliviano (Puma concolor) en el Parque Nacional Sajama (PNS) y relaciones con otras poblaciones de pumas del noroccidente de Sudamérica
}

\author{
Genetic characterization of the Bolivian Andean puma (Puma concolor) at the Sajama \\ National Park (SNP) and relationships with other north-western South American puma \\ populations
}

MANUEL RUIZ-GARCÍA ${ }^{1,}$, LUIS F. PACHECO ${ }^{2,3}$, DIANA ÁLVAREZ ${ }^{1}$

\author{
${ }^{1}$ Unidad de Genética (Genética de Poblaciones Molecular-Biología Evolutiva) Departamento de Biología. Facultad de \\ Ciencias. Pontificia Universidad Javeriana Carretera 7ª 43-82, Bogotá DC, Colombia \\ ${ }^{2}$ Centro de Estudios en Biología Teórica y Aplicada (BIOTA), Bolivia \\ ${ }^{3}$ Centro de Postgrado en Ecología y Conservación, Instituto de Ecología, Bolivia \\ *e-mail para correspondencia: mruiz@javeriana.edu.co
}

\begin{abstract}
RESUMEN
Se analizaron originalmente 25 muestras fecales de puma andino boliviano para proceder a su extracción de ADN. De esas 25 muestras, se detectaron cinco pumas diferentes que, junto, a tres de pieles de animales cazados, completaron un total de ocho pumas andinos bolivianos analizados. Igualmente se analizaron 45 muestras de ADN procedentes de pumas silvestres de Colombia, Perú, Ecuador, Venezuela y Amazonía occidental brasileña obtenidas a partir de mechones de pelos con bulbo, trocitos de pieles, músculo y dientes. Todas ellas se genotipificaron para siete marcadores microsatélites (Fca 08, 24, 43, 45, 96, 126 y 391). Los niveles de diversidad genética resultaron muy elevados en ambas muestras $(\mathrm{H}=0,942$ y 0,845 ; respectivamente), con valores muy superiores a los reportados para pumas norteamericanos. Diversos análisis de asignación poblacional mostraron que los pumas andinos bolivianos no formaron un grupo consistentemente diferente del otro grupo de pumas analizado. Únicamente un marcador, Fca 96, mostró heterogeneidad genética significativa entre ambos grupos. Sin embargo, globalmente, esa heterogeneidad fue extremadamente pequeña $\left(\mathrm{F}_{\mathrm{ST}}, \mathrm{G}_{\mathrm{ST}}, \mathrm{R}_{\mathrm{ST}}\right)$. Por el contrario, las estimas de flujo génico entre ambas agrupaciones fueron elevadas para todos los procedimientos empleados. La estimación del parámetro $\theta\left(=4 \mathrm{~N}_{\mathrm{e}} \mu\right)$ mediante el método de máxima verosimilitud de Nielsen (1997) mostró que la muestra boliviana es una extensión indiferenciable de la otra agrupación de pumas de otros países latinoamericanos. Por lo tanto, este estudio aporta resultados concluyentes en favor de un único acervo genético de pumas en el nor-occidente de Sudamérica, en contraste con las tradicionales clasificaciones morfológicas y morfométricas que habían identificado un número considerable de subespecies de puma en esta región de Latinoamérica.
\end{abstract}

Palabras clave: puma, Puma concolor, microsatélites de ADN, genética de poblaciones, Bolivia.

\begin{abstract}
Twenty-five Andean Bolivian fecal samples were obtained for extracting DNA. Five different Andean Bolivian pumas were detected and together with three skins of animals hunted completed eight Andean Bolivian pumas studied here. Additionally, 45 DNA samples from wild pumas from Colombia, Peru, Ecuador, Venezuela and western Brazilian Amazon were analyzed by means of hair with roots, little pieces of skins, muscle tissues and teeth. All these 53 puma DNA were genotypified for seven microsatellites (Fca $08,24,43,45,96,126$ and 391). The levels of gene diversity were very high in both sample groups $(\mathrm{H}=$ 0.942 and 0.845 , respectively), with values considerably higher than those found in the North American pumas. Diverse population assignment analyses showed that the Bolivian Andean pumas did not form a different significant cluster from the other puma group studied. Only Fca 96 showed significant heterogeneity between both groups. Nevertheless, globally, this heterogeneity was very small $\left(\mathrm{F}_{\mathrm{ST}}, \mathrm{G}_{\mathrm{ST}}\right.$, $\mathrm{R}_{\mathrm{ST}}$ ). On the contrary, the gene flow estimates between both groups were very elevated for all the procedures performed. The estimation of the parameter $\theta\left(=4 \mathrm{~N}_{\mathrm{e}} \mu\right)$, by means of the maximum likelihood procedure of Nielsen (1997), showed that the Bolivian sample is a similar extension of the puma population of the other Latin American countries analyzed. Therefore, this study yielded strong results in favor of an
\end{abstract}


unique gene pool of pumas in north western South America, in contrast with the traditional morphology and morphometric classifications which had identified a considerable number of puma subspecies in this region of Latin America.

Key words: puma, Puma concolor, DNA microsatellites, population genetics, Bolivia.

\section{INTRODUCCIÓN}

El puma (Puma concolor Linnaeus, 1771) es el mamífero de mayor tamaño, junto con el hombre, de distribución más amplia en América. Se le encuentra desde el norte de la Columbia Británica (ríos Big Muddy y Peas territorio del Yukón) en Canadá hasta el sur de Chile y Argentina (estrecho de Magallanes). Abarca ambientes de todo tipo, desde desiertos áridos a bosques húmedos tropicales, con rangos de altitud que alcanzan los $5.800 \mathrm{~m}$ (Curier 1983, Nowell \& Jackson 1996). No parece que su distribución dependa de la presencia de una especie particular (Young \& Goldman 1946). En Estados Unidos de Norteamérica los pumas han sido utilizados como una especie indicadora para conectividad de hábitat, al igual que como especie de gran valor desde la perspectiva de la conservación biológica (Beier 1993, Penrod 2000, Logan \& Sweanor 2001) por lo que la cantidad de estudios genéticos y ecológicos con esta especie son abundantes en aquel país.

Los pumas arribaron a Sudamérica entre 2 y 4 millones de años atrás, durante el gran intercambio de mamíferos eutéridos que se produjo con la formación del puente panameño (Webb \& Marshall 1981, Webb \& Rancy 1996). Sin embargo, como muestran Culver et al. (2000), los actuales pumas norteamericanos parecen haber derivado recientemente de los pumas sudamericanos hace unos 10.000 años.

$\mathrm{Su}$ distribución en Bolivia incluye también todo tipo de ambiente en áreas con poca influencia humana, aunque se le ha registrado ocasionalmente en áreas suburbanas (Pacheco \& Salazar 1996). Sin embargo, la presencia del puma en el altiplano boliviano no es común, al menos en las áreas alejadas de cordilleras y serranías, donde la agricultura es más intensiva y la cobertura de vegetación, y posibles guaridas, es relativamente menor. En cambio, en áreas próximas a las cordilleras, como en el Parque Nacional Sajama (PNS), el puma parece ser común (Pacheco \& Salazar 1996). El Parque Nacional Sajama (PNS) se encuentra ubicado en el Departamento de Oruro (Bolivia) $17^{\circ} 55^{\prime}-18^{\circ} 15^{\prime}$ 'S y $68^{\circ} 41^{\prime}-69^{\circ} 10^{\prime}$ O, colindante con el Parque Nacional Lauca de Chile de aproximadamente $1.378 \mathrm{~km}^{2}$. El PNS abarca una superficie de aproximadamente $1.020 \mathrm{~km}^{2}$ y un rango de altitudes entre 4.200 y $6.500 \mathrm{~m}$. La estación de lluvias se extiende desde noviembre a marzo o abril, con una precipitación de $400 \mathrm{~mm}$ anuales. El Parque incluye las ecorregiones altoandina occidental y Puna seca.

Poblaciones de pumas con niveles muy bajos de variabilidad genética pueden encontrase en una situación crítica desde el punto de vista de su conservación (O’Brien 1994). Este es el caso, por ejemplo, del puma de Florida. Roelke et al. (1993) mostraron que los niveles de variabilidad genética en esta población son extremadamente pequeños debido a la endogamia ocasionada por un número considerablemente disminuido de reproductores (menos de 30 individuos en Big Cypress Swamp y en el parque Nacional Everglades) y alejada por más de $2.000 \mathrm{~km}$ de la población más cercana. Asociado con este nivel de reducida variabilidad genética se encontraron diversos problemas. (1) Una enorme anormalidad espermática. De hecho, esta población de pumas ha mostrado la peor calidad en el semen de cualquier población, o especie, analizada de felinos $(94,3 \%$ de espermatozoides anómalos por eyaculado). La motilidad de los espermatozoides es de 18 a 38 veces inferior a la encontrada en cualquier otra subespecie de puma y es de 30 a 270 veces más pequeña que la determinada en otras especies de felinos, incluyendo el guepardo (Acynonix jubatus Schreber, 1775) (Roelke et al. 1993). (2) Elevada incidencia de criptorquidia (56\% de los machos observados desde 1978). Esta ausencia del descenso de los testículos no se ha observado en ninguna otra especie de felino silvestre. De hecho, el $90 \%$ de los machos vivos de esta población son criptorquídicos (Roelke et al. 1993). (3) Aparición de anomalías cardiacas (defecto del septo atrial). Además, el $80 \%$ de los pumas de Florida 
presentan ruidos cardiacos anómalos (Roelke et al. 1993). (4) Mayor incidencia de enfermedades infecciosas. En 1993, al menos ocho pumas habían muerto por patógenos infecciosos (Escherichia coli Migula, 1895, Streptococus equisimilus Chester, 1901, Clostridium sp., Pseudomonas aeruginosa Schroeter, 1872) (Roelke et al 1993). Por ello, es importante determinar cuál es el nivel de diversidad genética del puma andino boliviano.

Para ello, en el presente estudio, se aplicaron siete microsatélites nucleares a muestras de ADN obtenidas de excrementos de pumas muestreados en el interior del PNS, tres fragmentos de pieles de pumas procedentes del Departamento de La Paz y del Departamento de Cochabamba (total ocho pumas del altiplano boliviano), además de 45 pumas procedentes de diversas regiones de Colombia en los Departamentos de Atlántico, Bolívar, Risaralda, Valle del Cauca, Vaupés (río Itilla), Vichada (El Tuparro) y Amazonas (Araracuara en el río Caquetá; Leticia en el río Amazonas; Chorrera en el río Apaporis), de Ecuador (Amazonía ecuatoriana), de Perú (región de Loreto, Amazonía peruana, ríos Amazonas, Napo, Ucayali y Marañón), Venezuela (llanos venezolanos) y Brasil (Amazonía occidental y central de este país; ríos Yavarí y Negro).

Los objetivos principales del presente trabajo fueron: (1) proporcionar información acerca de características genético poblacionales (variabilidad genética, heterogeneidad genética) de los pumas en la citada región de los Andes bolivianos mediante el análisis de siete loci microsatélites hiperpolimórficos a partir de un método no invasivo (heces y fragmentos de pieles de animales ya muertos), y (2) determinar posibles diferencias genéticas entre esta población andina boliviana y los pumas de otros países latinoamericanos (Colombia, Ecuador, Perú, Venezuela y Amazonía brasileña occidental). Con esta información se evalúa la hipótesis de Culver et al. (2000) en cuanto a que la población de pumas del noroccidente de Sudamérica constituye un único linaje genético.

\section{MATERIALES Y MÉTODOS}

El primer tipo de muestras analizadas consistieron en 25 muestras fecales, las cuales fueron recolectadas en el PNS en noviembre de 2000 utilizando un sistema de transectos. Las heces frescas fueron enviadas al laboratorio de Genética de Poblaciones Molecular y Biología Evolutiva del Departamento de Biología de la Pontificia Universidad Javeriana en Bogotá (Colombia) envueltas en una gasa saturada en etanol $75 \%$ y donde se procedió a su análisis molecular. Igualmente, se extrajo ADN de tres muestras de pieles de pumas cazados en el altiplano boliviano (una muestra del sur del Departamento de La Paz y dos muestras del Departamento de Cochabamba en una zona cercana al Departamento de Oruro; muestras obtenidas por M. R-G). De las muestras de excrementos se identificaron cinco individuos diferentes, que junto a las tres muestras de pieles completaron los ocho pumas andinos bolivianos analizados en el presente estudio (Fig. 1). En paralelo se analizaron 45 pumas diferentes procedentes de diversas regiones de Colombia en los departamentos de Atlántico, Bolívar, Risaralda, Valle del Cauca, Vaupés (río Itilla), Vichada (El Tuparro) y Amazonas (Araracuara en el río Caquetá; Leticia en el río Amazonas; Chorrera en el río Apaporis), de Ecuador (Amazonía ecuatoriana), de Perú (región de Loreto, Amazonía peruana, ríos Amazonas, Napo, Ucayali y Marañón), Venezuela (llanos venezolanos) y Brasil (Amazonía occidental y central; ríos Yavarí y Negro) (Fig. 1). Las muestras consistieron en trozos de piel, dientes, mechones de pelos con bulbo o pequeños trozos de músculo. Trozos de pieles y dientes fueron empaquetados en bolsas de plástico y marcados correspondientemente. Mechones de pelo y músculos fueron introducidos en viales con etanol absoluto inmediatamente después de su recolección y marcados convenientemente. Por primera vez se reportan resultados moleculares para una muestra de pumas bolivianos, colombianos y peruanos procedentes de vida silvestre.

\section{Procedimientos moleculares}

La técnica de extracción de ADN a partir de las muestras fecales siguió el protocolo establecido por Ernest et al. (2000) y la extracción de ADN a partir de los trocitos de pieles, dientes y sangre se llevó a cabo a partir de una pequeña modificación del método del fenol-cloroformoalcohol isoamílico de Sambrook et al. (1989). 
Las extracciones de ADN nuclear de las células que envuelven la raíz del pelo se llevó a cabo con la resina Chelex al $10 \%$ (Walsh et al. 1991). Una vez que el ADN fue extraído, se analizaron siete microsatélites. Esos marcadores fueron Fca 08, Fca 24, Fca 43, Fca 45, Fca 96, Fca 126 y Fca 391. Adicionalmente, se analizaron otros marcadores en las muestras de pumas bolivianos (Fca 176, Fca 200, Fca 225, Fca 294 y Fca 506), pero los alelos obtenidos no pudieron ser comparados con los pumas de otras regiones de Sudamérica, ya que, previamente, esos otros ejemplares no fueron genotipificados para los mismos marcadores. Todos esos microsatélites poseen repeticiones dinucleotídicas (CA o GT), con la excepción de Fca 391 que posee una repetición tetranucleotídica. Las secuencias de las regiones flanqueantes de esos microsatélites fueron obtenidas por Menotti-Raymond \& O'Brien (1995) y Menotti-Raymond et al. (1999). La reacción en cadena de la polimerasa (PCR) fue realizada en un volumen de $50 \mu \mathrm{l}$. Las cantidades de reactivos por PCR incluyeron $5 \mu \mathrm{l}$ de $\mathrm{MgCl}_{2} 2,5 \mathrm{mM}, 5 \mu \mathrm{l}$ de Buffer 10x, $2 \mu \mathrm{l}$ de dNTPs $1 \mathrm{mM}, 20$ pmol de cada cebador, 14 $\mu \mathrm{l}$ de $\mathrm{H}_{2} 0,20 \mathrm{ml}$ de DNA y 2 unidades de Taq polimerasa para las muestras de ADN extraídas de los excrementos y de los pelos, utilizándose la mitad de los reactivos en el caso de las muestras de ADN extraídas de las pieles, dientes y sangre. Las reacciones de la PCR se llevaron a cabo en un termociclador Geneamp PCR System 9600 de Perkin Elmer (Wellesley,

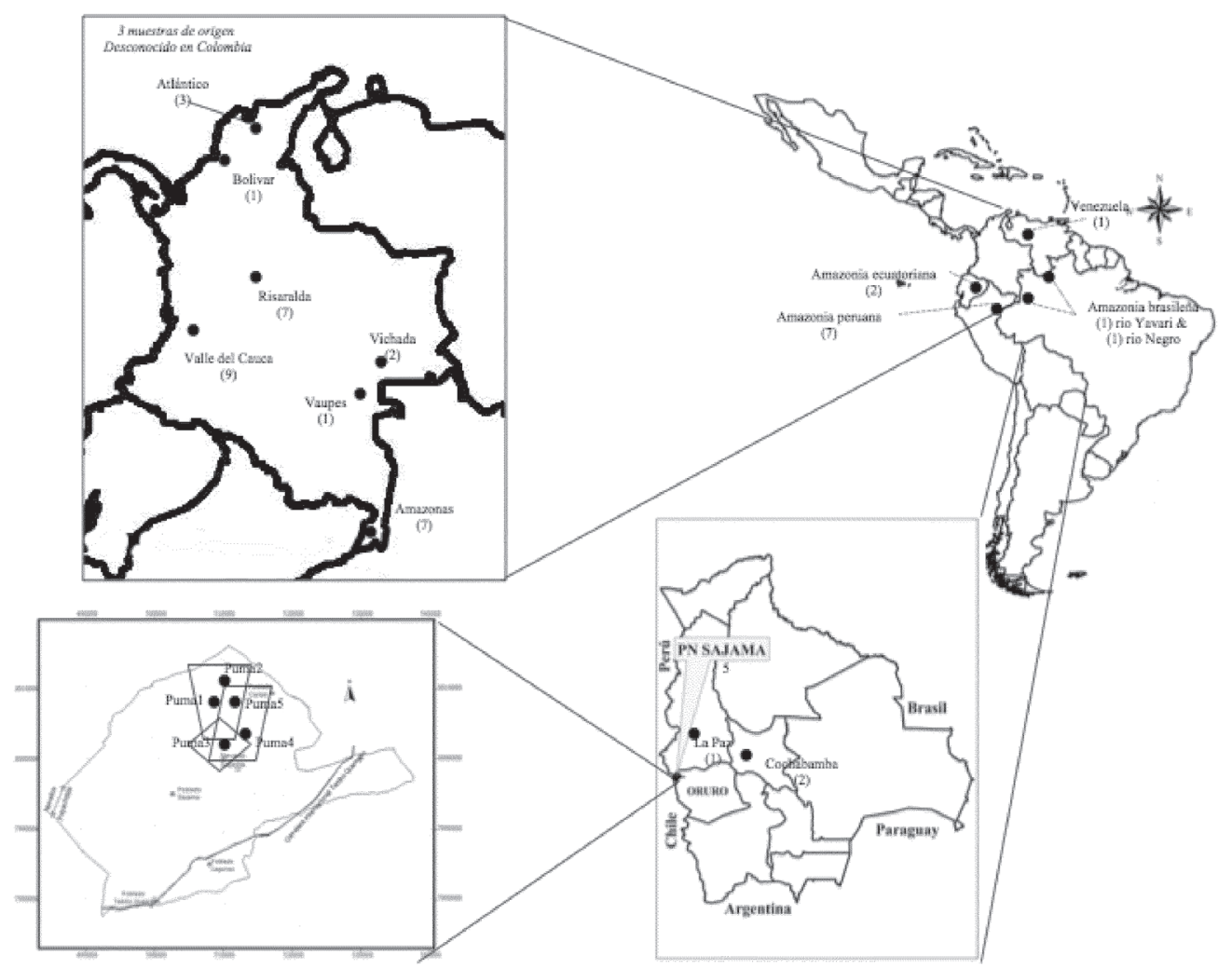

Fig. 1: Origen geográfico y número de muestras de puma (Puma concolor) analizadas en Bolivia y en otros países latinoamericanos, con especial detalle de las muestras obtenidas en Colombia. Entre paréntesis se indica el número de individuos analizados en cada área.

Geographical origin and number of samples of the pumas (Puma concolor) analyzed in Bolivia and in other Latin American countries, with special detail in the samples obtained in Colombia. The number of individuals sampled in each area is indicated in parentheses. 
Massachusetts). Las temperaturas empleadas fueron las siguientes: $95{ }^{\circ} \mathrm{C}$ por $5 \mathrm{~min} ; 35$ ciclos de 1 min a $95{ }^{\circ} \mathrm{C}, 2 \mathrm{~min}$ a $55^{\circ} \mathrm{C}$, y $2 \mathrm{~min}$ a $72{ }^{\circ} \mathrm{C}$ para todos los marcadores empleados. Se utilizó una extensión final de $5 \mathrm{~min}$ a $72{ }^{\circ} \mathrm{C}$. Los productos de la PCR fueron corridos en geles de poliacrilamida al $6 \%$ denaturados en una cámara vertical de secuenciación Hoefer SQ3. La tinción de los geles se realizó con nitrato de plata. El tamaño de los alelos fue obtenido por comparación con un marcador de peso molecular ( $\phi$ X174 DNA, digerido con las enzimas Hind III y Hinf I). Las amplificaciones de PCR se replicaron tres veces para determinar la precisión de los genotipos obtenidos y no tener falsos homocigotos por no amplificación específica de un alelo (Taberlet et al. 1996, 1999).

\section{Análisis genético poblacional}

La diversidad genética se midió usando la estima no sesgada de la heterocigosis esperada (Nei 1978). Tal como Nei (1973) estableció, este estadístico es sumamente importante como medida de la variación genética ya que es independiente del número observado de individuos heterocigotos, con lo que es independiente de selección favorable o contraria, para homo y/o heterocigotos, y de las estrategias reproductivas en el seno de la población. Una pérdida significativa de la heterocigosis media esperada puede indicar claramente la acción de diferentes procesos estocásticos, como la deriva genética, o de selección actuando en contra de un alelo particular $\mathrm{y}$, por lo tanto, modificando las frecuencias alélicas (Ruiz-García 1991). Se contrastó el valor obtenido de la diversidad genética en la muestra boliviana respecto a la diversidad genética obtenida en el conjunto global de las restantes muestras de pumas (Colombia, Ecuador, Perú, Venezuela y Brasil) para determinar si los animales bolivianos poseen una reducida fracción, o no, de la variabilidad genética global encontrada en otras regiones de Sudamérica. Ello nos puede indicar si los pumas del altiplano boliviano han pasado por algún evento de cuello de botella o disminución de sus números poblacionales que haya disminuido su variabilidad genética.

Se llevó a cabo una prueba de asignación poblacional para determinar si los animales bolivianos analizados presentaron perfiles multigenotípicos diferenciables de los pumas de otras regiones de Sudamérica. Este análisis se realizó mediante el programa GENECLASS 2.0 (Cornuet et al. 1999, Piry et al. 2004). Para ello, se aplicaron métodos basados en teoría bayesiana (Rannala \& Mountain 1997, Badouin \& Lebrun 2000), en frecuencias (Paetkau et al. 1995) y en distancias genéticas. Este último método se fundamenta en la asignación de individuos a la población más cercana y requiere de la definición de distancias genéticas entre los individuos y las poblaciones consideradas. Se utilizaron las distancias de Nei (1978), mínima de Nei (1978), DA de Nei et al. (1983), de Cavalli-Sforza \& Edwards (1967) y la distancia genética $\delta \mu^{2}$ (Goldstein et al. 1995). El análisis de asignación con cada uno de esos procedimientos fue llevado a cabo sin simulaciones y calculando probabilidades de pertenencia, o exclusión, de los individuos a los grupos $(\mathrm{P}<0,01)$ mediante simulaciones con 10.000 remuestreos mediante la técnica de Monte Carlo y aplicando el procedimiento de Paetkau et al. (2004). También se determinó la posible existencia de migrantes de primera generación en ambos grupos de pumas. Para ello, al igual que en el caso anterior, se aplicaron métodos bayesianos, de frecuencias y de distancias genéticas sin simulaciones y con simulaciones (10.000 remuestreos con la técnica de Monte Carlo) aplicando los métodos de Paetkau et al. (2004), Cornuet et al. (1999) y Rannala \& Mountain (1997). Para la determinación de los individuos migrantes de primera generación se tuvo en consideración la expresión $\mathrm{L}=$ Lhome/Lmax, la cual es el cociente de la verosimilitud de la población donde un individuo determinado fue muestreado respecto a la verosimilitud más elevada encontrada para todas las poblaciones muestreadas, incluyendo la de procedencia (Paetkau et al. 2004). Para constatar los resultados obtenidos mediante la estrategia de asignacion, se procedio a obtener un árbol UPGMA con la distancia DAS (alelos compartidos; Chakraborty \& Jin 1993) entre los 53 individuos estudiados con el programa POPULATIONS 1.2.30 (Langella 1999).

Por otra parte se determinó la heterogeneidad genética entre la muestra boliviana y la muestra de los otros países latinoamericanos usando probabilidades exactas mediante cadenas de 
Markov (Raymond \& Rousset 1995) con 10.000 demorizaciones, 100 batches y 5.000 iteraciones por batch. Este análisis también se aplicó a las muestras analizadas por pares de países para detectar una posible estructura a un nivel geográfico más restringido. Igualmente, se aplicó un análisis jerárquico con los estadísticos F de Wright (1951), un análisis de diversidad génica de Nei (1973) y la estima del estadístico $\mathrm{R}_{\mathrm{ST}}$ (Slatkin 1995) con tres procedimientos diferentes (ponderado, Goodman 1997 y no ponderado). La significación estadística de los estadísticos $\mathrm{F}$ fue realizada mediante 2.000 permutaciones “jackknife" y 2.000 permutaciones "bootstrap".

A partir de los estadísticos $\mathrm{F}_{\mathrm{ST}}$ (obtenido con el método de Weir \& Cockerham 1984), $\mathrm{G}_{\mathrm{ST}}$ (obtenido con el procedimiento de Nei 1973) y $\mathrm{R}_{\mathrm{ST}}$ (obtenido con el método de Goodman 1997) se obtuvieron estimas indirectas de flujo génico entre la población boliviana y el resto de poblaciones mediante un modelo infinito de islas (Ruiz-García 1993, 1998, Ruiz-García \& Álvarez 2000) y un modelo isla n-dimensional (Takahata 1983, Crow \& Aoki 1984). Igualmente, se obtuvo una estima de flujo génico entre ambas poblaciones con el método de los alelos privados (Slatkin 1985, Barton \& Slatkin 1986).

Finalmente, se determinaron estimas de tamaños efectivos históricos a largo término (número promedio de reproductores a lo largo de todas las generaciones de una especie) de la población boliviana respecto al conjunto de las otras poblaciones de pumas estudiadas. Para ello, se aplicó el procedimiento de Nielsen (1997). Esta técnica se fundamenta en un método de máxima verosimilitud con cadenas de Markov recursivas para estimar el valor más probable de $\theta\left(=4 \mathrm{~N}_{\mathrm{e}} \mu\right)$, siendo $\mathrm{N}_{\mathrm{e}}$ el tamaño poblacional efectivo y $\mu$ la tasa de mutación por generación. Nielsen (1997) aplicó la recursividad de la teoría de la coalescencia para obtener funciones de verosimilitud de $\theta$ para muestras de un tamaño determinado. Para ello, se aplicó el programa MISAT (Nielsen 1997) con un millón de cadenas de Markov. La estima de máxima verosimilitud de q con probabilidad más elevada es aquella con el valor del logaritmo de verosimilitud menos negativo. Del valor de $\theta$ más probable, se puede despejar $\mathrm{N}_{\mathrm{e}}$ asumiendo diversas estimas de las tasas de mutación por generación obtenidas para otros mamíferos: de $2,5 \times 10^{-4}$ (Rooney et al. 1999) a $5,6 \times 10^{-4}$ (Weber \& Wong 1993).

\section{RESULTADOS}

De las 25 muestras de heces recolectadas, se detectaron cinco pumas diferentes (Fig. 2) con una probabilidad de diferenciación de los perfiles multigenotípicos de 0,9976. El número promedio de alelos por marcador para los ejemplares bolivianos fue de 3,857 $\pm 1,464$ (Tabla 1). Este valor fue significativamente inferior al encontrado para el conjunto de pumas de otras regiones de Sudamérica (11 \pm $3,916)$. Sin embargo, este estadístico está fuertemente influenciado por el tamaño de la muestra (ocho ejemplares frente a 45) y no es de extrañar la diferencia encontrada. Por el contrario, cuando se comparó la proporción de heterocigotos observados en ambos grupos de pumas $(0,592 \pm 0,183$ en Bolivia y 0,629 \pm 0,117 en la restante muestra), los valores fueron prácticamente idénticos $(\mathrm{t}=0,26 ; \mathrm{P}>$ $0,05)$. La diversidad genética (= heterocigosis esperada) fue, incluso, más elevada en el conjunto de pumas bolivianos $(0,942 \pm 0,107)$ que en el grupo de pumas de los otros países sudamericanos estudiados $(0,845 \pm 0,091)$, aunque no de forma significativa $(\mathrm{t}=0,95 ; \mathrm{P}>$ $0,05)$. Esos niveles de variabilidad genética son muy elevados. Algunos de los alelos encontrados fueron exclusivos de los pumas bolivianos. Estos fueron los casos de un alelo de 199 pb para Fca 96, de un alelo de 127 pb para Fca 126, de un alelo de 126 pb para Fca 08 y de un alelo de 234 pb para Fca 24. Para los marcadores Fca 391, Fca 43 y Fca 45 no se encontraron alelos privados en la muestra boliviana.

El análisis de asignación multigenotípico presentó diversos resultados en función de los procedimientos utilizados (Tabla 2). Los métodos bayesianos, sin simulaciones, fueron los que peor porcentaje de asignación mostraron. Únicamente clasificaron correctamente entre un 52,8\% (Baudovin \& Lebrun 2000) y un 62,17 \% (Rannala \& Mountain 1997) de los pumas analizados. En el primer caso, dos pumas bolivianos presentaron más posibilidades de pertenecer al grupo de los restantes pumas sudamericanos que al propio grupo geográfico; tres en el caso del segundo 
método. Con el procedimiento de las frecuencias, el porcentaje de correcta asignación fue del $77,4 \%$, con cuatro pumas bolivianos presentando mayores posibilidades de pertenencia al otro grupo geográfico. Con el método de las distancias genéticas, los porcentajes de correcta asignación oscilaron entre $64,15 \%\left(\delta \mu^{2}\right)$ y $79,24 \%$ (distancia mínima de Nei). En todos los casos, entre cinco $\mathrm{y}$ seis pumas bolivianos presentaron mejores valores de asignación en el grupo de los restantes pumas que en el suyo propio. Esto significa que los pumas bolivianos estudiados no poseen características genéticas propias que

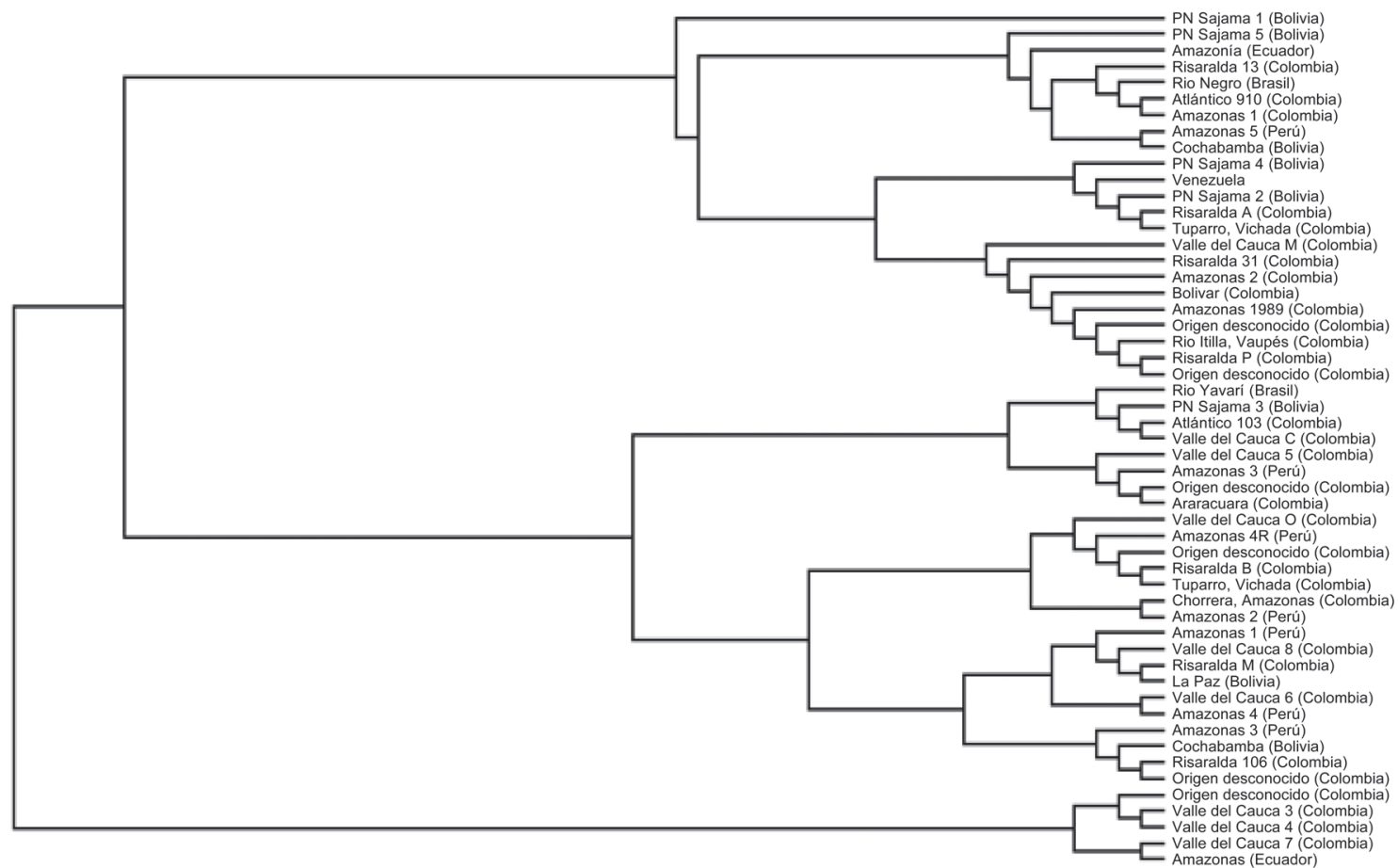

Fig. 2: Fenograma con el algoritmo UPGMA y con la distancia de los alelos compartidos (DAS) con los 53 pumas analizados para siete marcadores de ADN microsatelite.

Phenogram with the UPGMA algorithm and with the distance of the allele shared (DAS) with the 53 pumas analyzed at seven microsatellite DNA markers.

\section{TABLA 1}

Número promedio de alelos por locus, proporción de heterocigotos observados y promedio de la diversidad génica de Nei (1973) (= heterocigosis esperada) para siete microsatélites (Fca 08, 24, 43, 45, 96, 126 y 391) estudiados en dos muestras de pumas, una procedente del altiplano de Bolivia y otra (*) de pumas muestreados en vida silvestre en Colombia, Perú, Ecuador, Venezuela y fracción occidental de la Amazonía brasileña

Average allele number per locus, proportion of observed heterozygosity and average Nei's (1973) gene diversity (= expected heterozygosity) for seven microsatellites (Fca 08, 24, 43, 45, 96, 126 y 391) analyzed in two puma samples, one from the Bolivian highlands and other (*) from pumas sampled in wild life in Colombia, Perú, Ecuador, Venezuela and western Brazilian Amazon

\begin{tabular}{lcr}
\hline Parámetro & Total* & Bolivia \\
\hline Número promedio de alelos por locus & $11 \pm 3,916$ & $3,857 \pm 1,464$ \\
Proporción de heterocigotos observados & $0,629 \pm 0,117$ & $0,592 \pm 0,183$ \\
Promedio de la diversidad génica de Nei (1973) & $0,844 \pm 0,090$ & $0,942 \pm 0,107$ \\
\hline
\end{tabular}


los diferencien de los otros pumas analizados. Esto es, genéticamente son muy similares a los pumas de los otros países sudamericanos aquí reportados para los siete loci microsatélites de ADN empleados, lo cual es síntoma, al menos, de un elevado flujo génico histórico. Con los métodos de asignación utilizando simulaciones (Paetkau et al. 2004), para calcular probabilidades significativas de pertenencia a un grupo específico, los porcentajes de asignación correcta fueron similares al caso anterior. La peor asignación correspondió a la distancia DA de Nei et al. (1983) (71,7\%) y la mejor a la distancia de Nei (1978) (82\%). En cuanto a los ejemplares bolivianos, en ningún caso, quedaron bien diferenciados del grupo de pumas de las otras localidades sudamericanas estudiadas. Con ambos métodos bayesianos, ninguno de los ocho ejemplares analizados perteneció significativamente a ninguno de los dos grupos. Con el método de la distancia de Nei, seis pumas presentaron probabilidades de poder pertenecer a ambos grupos, uno sería inclasificable y otro sería significativamente más parecido al grupo de pumas sudamericanos de otros países. Finalmente, con la distancia mínima de Nei, tres pumas bolivianos serían significativamente más parecidos al grupo de pumas de otras localidades sudamericanas, dos presentarían probabilidades similares de pertenecer a ambos grupos, dos serían significativamente diferentes de ambos grupos y uno pertenecería claramente a un acervo boliviano diferente del acervo de pumas de otras localidades sudamericanas. Como puede comprobarse, los pumas bolivianos no se diferencian claramente de los pumas analizados procedentes de Colombia, Ecuador, Perú, Venezuela y Amazonía occidental brasileña para los marcadores microsatélites utilizados.

TABLA 2

Análisis multigenotípico de asignación de los ocho pumas bolivianos analizados respecto al grupo de 45 muestras de pumas procedentes de Colombia, Perú, Ecuador, Venezuela y fracción occidental de la Amazonía brasileña. G1 = Grupo de pumas bolivianos. G2 = Grupo de pumas colombianos, venezolanos, ecuatorianos, peruanos y de la Amazonía occidental brasileña

Multi-genotypic assignment analysis of the eight Bolivian pumas analyzed regard to the group of 45 pumas studied from Colombia, Perú, Ecuador, Venezuela and western Brazilian Amazon. G1 = Bolivian puma set. G2 = Colombian, Venezuelan, Equatorian, Peruvian and western Brazilian Amazon puma set

Método de Asignamiento Índice decalidad Asignamiento correcto Animales bolivianos mal clasificados $(\%)$ $(\%)$

Sin simulación

62,17

55,29

Baudovin \& Lebrun

73,02

Frecuencias

Distancia de Nei

Distancia Mínima de Nei

Distancia DA

Distancia Cavalli-Sforza \& Edwards

Distancia $\mathrm{d} \mu^{2}$

Con simulación (remuestreo de Monte Carlo, $\mathrm{P}<0,01$ )

Rannala \& Mountain

Baudovin \& Lebrun

Frecuencias

Distancia de Nei

Distancia Mínima de Nei

Distancia DA

Distancia Cavalli-Sforza \& Edwards

Distancia $\mathrm{d} \mu^{2}$

71,59
56,50
70,07
75,68
64,05
60,56
60,40
67,85

71,59

70,07

75,68

64,05

60,56

67,85

$\begin{array}{ll}60,40(32 / 53) & 3 / 8 \\ 52,80(28 / 53) & 2 / 8 \\ 77,40(41 / 53) & 4 / 8 \\ 75,47(40 / 53) & 6 / 8 \\ 79,24(42 / 53) & 6 / 8 \\ 75,47(40 / 53) & 5 / 8 \\ 73,58(39 / 53) & 5 / 8 \\ 64,15(34 / 53) & 6 / 8\end{array}$

$77,4(41 / 53)$

0

0

2 a G2 y2 con igual probabilidadA G1 y G2 1 a G2 y6 igual probabilidadA G1 y G2 3 a G2 y2 igual probabilidadA G1 y G2 todos indistinguibles de G2 todos indistinguibles de G2 todos indistinguibles de G2 
El análisis de determinación de migrantes de primera generación sin simulaciones mostró claramente que el grupo boliviano de pumas y el restante grupo han intercambiado una fracción considerable de individuos. Los métodos bayesianos identificaron, respectivamente, dos (Baudovin \& Lebrun 2000) y tres (Rannala \& Mountain 1997) pumas bolivianos como migrantes de primera generación procedentes del grupo restante. El método de las frecuencias identificó cuatro animales bolivianos (50\% de los ejemplares analizados) como procedentes del grupo global. Tres de los métodos de distancias, identificaron seis de los ocho pumas bolivianos genotipificados como migrantes procedentes del grupo de las otras localidades sudamericanas, mientras que otros dos métodos de distancias identificaron cinco pumas bolivianos como migrantes del grupo de las otras localidades sudamericanas. Cuando se aplicó el método con simulaciones utilizando el procedimiento de Paetkau et al. (2004), con los dos métodos bayesianos, frecuencial y de las distancias genéticas, se obtuvo una diversidad de resultados diferentes. Los métodos bayesianos y frecuencial detectaron entre dos y tres pumas bolivianos como migrantes de primera generación procedentes del otro grupo. Sin embargo, los métodos de distancias no detectaron significativamente ningún migrante de primera generación procedente del grupo de las otras localidades sudamericanas en el acervo boliviano. Para los procedimientos de Cornuet et al. (1999) y Rannala \& Mountain (1997) los resultados fueron idénticos. Los métodos bayesianos y frecuencial detectaron entre dos y cuatro pumas bolivianos como migrantes del grupo de las otras localidades sudamericanas, mientras que los métodos de distancias genéticas no detectaron ningún migrante en el seno del grupo boliviano. El hecho que una buena fracción de los métodos empleados detecte significativamente migrantes en el conjunto de pumas representativos del altiplano boliviano pone de manifiesto el trasiego de genes entre los pumas de esta región de Bolivia y de otras áreas de Sudamérica. Igualmente, el árbol UPGMA con la distancia DAS con los 53 ejemplares analizados mostró la inexistencia de agrupaciones geográficas bien consolidadas (Fig. 2). En dicho árbol se observaron tres agrupaciones. La agrupación más divergente contuvo cinco animales, tres del valle del Cauca (Colombia), uno de Ecuador y un animal colombiano de origen desconocido. La segunda agrupación mostró tres subagrupaciones. Por ejemplo, en una de ellas se encontraron ejemplares procedentes de los Andes bolivianos (dos animales), uno de la Amazonía ecuatoriana, uno del Departamento de Risaralda (Colombia), uno del río Negro (Brasil), uno de la costa Atlántica colombiana, un animal capturado cerca de Leticia, Amazonía colombiana y un animal del Departamento de Loreto, río Napo, en la Amazonía peruana. En la tercera agrupación, también, se aprecian otras tres subagrupaciones. Por ejemplo, la primera de ella contiene un puma del río Yavarí (Brasil), uno de los Andes bolivianos, uno de la costa Atlántica colombiana, dos del Departamento del Valle del Cauca (Colombia), uno de la Amazonía peruana, uno colombiano de origen desconocido y uno del Araracuara, río Caquetá, Amazonas colombiano. Se revela claramente que no existen agrupaciones geográficas consistentes y los animales de los Andes bolivianos están mezclados con los de otros orígenes geográficos.

Tanto en el grupo global, como en el boliviano, se detectó un cierto exceso de homocigotos $(\mathrm{F}=0,255$ y 0,372 , respectivamente) pero sin alcanzar una significación estadística $(\mathrm{P}>0,10)$. El análisis de diferenciación génica utilizando tests exactos con cadenas de Markov (Tabla 3) mostró que Fca 96 presentó heterogeneidad significativa entre el grupo boliviano y el grupo de otras localidades sudamericanas $(\mathrm{P}=$ $0,00017)$, al igual que el test combinado para todos los loci analizados simultáneamente con el método de Fisher $\left(\chi^{2}=35,78 ; \mathrm{gl}=14 ; \mathrm{P}=\right.$ $0,0011)$. Sin embargo, los restantes seis loci analizados individualmente no presentaron heterogeneidad significativa entre ambos grupos, lo cual muestra el relativo parecido genético de los pumas bolivianos respecto a los pumas de otras zonas de Sudamérica. Cuando el mismo análisis se realizó por pares de países se obtuvo el siguiente panorama. De las 105 comparaciones realizadas (15 comparaciones entre países por siete marcadores), solo seis revelaron una heterogeneidad genética significativa. Para Fca 96, las comparaciones Bolivia-Colombia $(P=0,00026 \pm 0,00007)$ y 
Bolivia-Perú $(0,00069 \pm 0,00011)$ resultaron significativas, para Fca 45, la comparación Perú-Colombia $(0,0025 \pm 0,00019)$ y BoliviaColombia $(0,000403+0,00028)$ resultaron significativas, para Fca 43, la comparación Brasil-Colombia $(0,00752+0,00048)$ también lo resultó y para Fca 08 , el caso Perú-Colombia $(0,03284 \pm 0,00122)$, también, fue significativo. Teniendo en cuenta los siete microsatélites simultáneamente, Colombia-Perú $\left(\chi^{2}=35,19 ; \mathrm{df}=12 ; \mathrm{P}=0,000437\right)$, ColombiaBrasil $\left(\chi^{2}=20,43 ;\right.$ df $\left.=10 ; \mathrm{P}=0,025415\right) \mathrm{y}$ Colombia-Bolivia $\left(\chi^{2}=43,91 ; \mathrm{df}=14 ; \mathrm{P}=\right.$ $0,000061)$ resultaron los tres casos significativos. Parece evidente que la población colombiana es la más diferenciada genéticamente respecto a la de los otros países del área estudiados, aunque fue la muestra de mayor tamaño y, por ende, con más capacidad de discriminación.

La aplicación de los estadísticos $\mathrm{F}$ de Wright (Tabla 4) mostró que todos los microsatélites individualmente empleados, con excepción de Fca 24, y todos tomados simultáneamente, presentaron un exceso de homocigotos significativo a nivel global de ambos grupos $\left(\mathrm{F}_{\mathrm{IT}}\right)$ y en promedio dentro de los grupos $\left(\mathrm{F}_{\mathrm{IS}}\right)$. La heterogeneidad genética más elevada fue la determinada para Fca $96\left(\mathrm{~F}_{\mathrm{ST}}=\right.$ $0,078 ; \mathrm{P}=0,0001)$, la cual fue significativa estadísticamente. También lo fue el valor promedio de $\left(\mathrm{F}_{\mathrm{ST}}=0,011 ; \mathrm{P}=0,0015\right)$, siendo ambos resultados consistentes con lo encontrado mediante pruebas de probabilidades exactas. No obstante, el valor promedio obtenido de la $\mathrm{F}_{\mathrm{ST}}$ es relativamente muy pequeño porque indica que cualquiera de las dos agrupaciones de pumas posee el 98,9\% de la variabilidad genética encontrada en la otra agrupación. Los valores procedentes del análisis de diversidad génica de Nei (1973) también revelaron niveles de heterogeneidad genética prácticamente nulos entre ambas agrupaciones de pumas $\left(\mathrm{G}_{\mathrm{ST}}=-0,001 ; \mathrm{G}_{\mathrm{ST}}{ }^{\prime}=\right.$ $-0,001)$. Los valores obtenidos por el estadístico $\mathrm{R}_{\mathrm{ST}}$, con tres procedimientos diferentes, oscilaron entre 0,0497 y 0,0745 . Esos valores aunque algo mayores que los obtenidos mediante los estadísticos $\mathrm{F}_{\mathrm{ST}}$ y $\mathrm{G}_{\mathrm{ST}}$ siguen mostrando una heterogeneidad genética relativamente baja entre ambas poblaciones de pumas. Con el estadístico $\mathrm{R}_{\mathrm{ST}}$, los marcadores Fca 08, Fca 126 y Fca 45 fueron los que detectaron mayor heterogeneidad genética.

A partir de los diversos estadísticos comentados, se realizaron estimas teóricas de flujo génico entre ambas poblaciones. Para el estadístico $\mathrm{G}_{\mathrm{ST}}$, tanto con un modelo infinito de islas como con un modelo n-dimensional, la estima de flujo génico $(\mathrm{Nm})$ fue infinita. Con la $\mathrm{F}_{\mathrm{ST}}$, se obtuvo una estima de $\mathrm{Nm}=22,47$ para el primer modelo y de $\mathrm{Nm}=5,62$ para el segundo. Con los diversos valores obtenidos de $\mathrm{R}_{\mathrm{ST}}$, las estimas de $\mathrm{Nm}$ fueron 3,37, 3,11 y 4,78 , respectivamente. La estima de $\mathrm{Nm}$ con el método de los alelos privados fue algo menor $(\mathrm{Nm}=1,29)$. Sin embargo, todas las estimas obtenidas pueden considerarse elevadas,

\section{TABLA 3}

Análisis de la heterogeneidad genética mediante tests exactos con cadenas de Markov entre dos muestras de pumas, una procedente del altiplano boliviano y otra de Colombia, Perú, Ecuador, Venezuela y fracción occidental de la Amazonía brasileña para siete marcadores microsatélites

(Fca 08, 24, 43, 45, 96, 126 y 391); (*) valores estadísticamente significativos $(\mathrm{P}<0,05)$

Genetic heterogeneity analysis by means of exact tests with Markov chains between two puma samples, one coming from the Bolivian highlands and other from Colombia, Perú, Ecuador, Venezuela and western Brazilian Amazon for 7 microsatellites (Fca 08, 24, 43, 45, 96, 126 y 391); (*) statistically significant values $(\mathrm{P}<0.05)$

\begin{tabular}{lccl}
\hline Marcadores & Valor de P & Error estándar & \\
\hline Fca 96 & $0,00017 *$ & 0,00006 & Combinación de todas las pruebas \\
Fca 126 & 0,08605 & 0,00201 & (método de Fisher) \\
Fca 45 & 0,13711 & 0,00207 & $\chi^{2}=35,7814$ \\
Fca 43 & 0,36020 & 0,00377 & $\mathrm{df}=14$ \\
Fca 08 & 0,28217 & 0,00434 & $\mathrm{P}=0,0011^{*}$ \\
Fca 391 & 0,50273 & 0,00617 & \\
Fca 24 & 0,16977 & 0,00324 & \\
\hline
\end{tabular}


mostrando que la población boliviana de pumas está conectada genéticamente con poblaciones de puma de Perú, Ecuador, Colombia, Venezuela y zona occidental de la Amazonía brasileña.

El último análisis aplicado fue el de Nielsen (1997), con un método de máxima verosimilitud mediante cadenas de Markov, para obtener el estadístico $\theta\left(=4 \mathrm{~N}_{\mathrm{e}} \mu\right)$ (Tabla $5)$. Este es un estadístico que mide la riqueza genética de una población y si se conoce un valor adecuado de $\mu$ (tasa de mutación por generación) permite la obtención de una estima muy precisa de los tamaños efectivos históricos a largo plazo de una población dada. La estima de q se llevó a cabo mediante el método de los momentos y el método referido de Nielsen (1997). Tanto para el grupo boliviano, como para la otra agrupación, la estima de $\theta$ con el método de los momentos resultó significativamente menor que la obtenida con el método de máxima verosimilitud (Bolivia: $\theta_{\mathrm{o}}$ $=27$ versus $\theta=39,08 ; \mathrm{t}=-2,821 ; \mathrm{gl}=6 ; \mathrm{P}=$ 0,0303 , prueba de rangos de Wilcoxon, $\mathrm{Z}=$ 2,201; $\mathrm{P}=0,0277$; Colombia, Ecuador, Perú,
Venezuela, Amazonía occidental brasileña: $\theta_{\mathrm{o}}$ $=29,33$ versus $\theta=39,81, \mathrm{t}=-3,676 ; \mathrm{gl}=6 ; \mathrm{P}=$ 0,0104 , prueba de rangos de Wilcoxon, $\mathrm{Z}=$ $2,366 ; \mathrm{P}=0,018)$. Sin embargo, no existieron diferencias significativas para ambos métodos al estimar q entre el grupo boliviano y la otra agrupación geográfica $(\mathrm{t}=0,145 ; \mathrm{gl}=6 ; \mathrm{P}=$ $0,876)$. Es más, esos valores son prácticamente idénticos lo que significa que la variabilidad genética de los pumas del altiplano boliviano es muy elevada y que, potencialmente, a lo largo de su historia esta población fue muy grande. Esto enfatiza que ambas poblaciones siempre constituyeron un único gran acervo genético (Bolivia, Perú, Ecuador, Colombia, Venezuela, Amazonía occidental brasileña), al tener en consideración la escasa heterogeneidad genética entre ambas agrupaciones. Con la estima de q obtenida mediante el método de los momentos, los valores de tamaños efectivos históricos fueron de 12.055 (Bolivia) y 13.094 (el restante grupo sudamericano estudiado) y con el método de máxima verosimilitud de Nielsen (1997) fueron de 17.447 (Bolivia) y de 17.774 (la otra agrupación geográfica)

TABLA 4

Estadísticos $\mathrm{F}$ de Wright $\left(\mathrm{F}_{\mathrm{IT}}, \mathrm{F}_{\mathrm{ST}}, \mathrm{F}_{\mathrm{IS}}\right)$ aplicados para el estudio de la repartición de la varianza genética entre dos agrupaciones de pumas (altiplano boliviano y otras áreas de noroeste de Sudamérica en Colombia, Perú, Ecuador, Venezuela y fracción occidental de la Amazonía brasileña); $\mathrm{R}_{\mathrm{ST}}=$ estadístico de heterogeneidad genética calculado a partir de marcadores microsatélites con el método de Slatkin (1995); (*) valores estadísticamente significativos $(\mathrm{P}<0,05) ; \mathrm{ns}=$ valores no significativos

Wright's $\mathrm{F}$ statistics $\left(\mathrm{F}_{\mathrm{IT}}, \mathrm{F}_{\mathrm{ST}}, \mathrm{F}_{\mathrm{IS}}\right)$ applied to the study of the repartition of the genetic variance between two puma groups (Bolivian highlands and other north-western South-American areas in Colombia, Perú, Ecuador, Venezuela and western Brazilian Amazon); $\mathrm{R}_{\mathrm{ST}}=$ genetic heterogeneity statistic calculated with the use of microsatellites designed by Slatkin (1995); (*) statistically significant values $(\mathrm{P}<0.05)$; ns = statistically non significant values

\begin{tabular}{lcccl}
\hline Marcadores & $\mathrm{F}_{\mathrm{IT}}$ & $\mathrm{F}_{\mathrm{ST}}$ & $\mathrm{F}_{\mathrm{IS}}$ & $\mathrm{R}_{\mathrm{ST}}$ \\
\hline Fca 96 & $0,362^{*}$ & $0,078^{*}$ & $0,115^{*}$ & $-0,042$ \\
Fca 126 & $0,327^{*}$ & $0,026 \mathrm{~ns}$ & $0,309^{*}$ & 0,244 \\
Fca 45 & $0,346^{*}$ & $-0,027 \mathrm{~ns}$ & $0,363^{*}$ & 0,178 \\
Fca 43 & $0,276^{*}$ & $-0,003 \mathrm{~ns}$ & $0,278^{*}$ & $-0,173$ \\
Fca 08 & $0,270^{*}$ & $-0,013 \mathrm{~ns}$ & $0,280^{*}$ & 0,275 \\
Fca 391 & $0,156^{*}$ & $-0,001 \mathrm{~ns}$ & $0,157^{*}$ & 0,052 \\
Fca 24 & $0,124 \mathrm{~ns}$ & $-0,008 \mathrm{~ns}$ & $0,131 \mathrm{~ns}$ & $-0,186$ \\
Jackknife & $0,011 \pm 0,014 *$ & $0,259 \pm 0,030^{*}$ & Ponderado \\
& & & 0,0691 \\
& & & & Método de Goodman \\
& & & & 0,0745 \\
& & & & No ponderado \\
\end{tabular}


mediante una estima de la tasa de mutación por generación de 5,6 x 10-4. Cuando la estima de la tasa de mutación empleada fue de $2,5 \times 10^{-4}$, los valores de los tamaños efectivos fueron, con el primer método, de 27.004 (Bolivia) y de 29.330 (la otra agrupación geográfica), mientras que, con el segundo método, esas estimas ascendieron a 39.082 (Bolivia) y 39.814 (la otra agrupación geográfica). En cualquier caso, los tamaños efectivos de la población boliviana de pumas serían prácticamente idénticos a los encontrados para otras zonas más extensas del noroccidente de Sudamérica, lo que significa que la primera población es prácticamente indiferenciable genéticamente de la segunda, teniendo en cuenta la escasa heterogeneidad genética encontrada entre ambas agrupaciones geográficas.

\section{DISCUSIÓN}

El primer comentario en esta sección debe destacar el número pequeño y limitado de pumas analizados en territorio boliviano. Esto puede tener implicaciones en la precisión de los resultados obtenidos pero cabe resaltar que es la primera vez que se consiguen resultados moleculares para pumas bolivianos procedentes directamente de vida silvestre (también para pumas colombianos y peruanos de origen silvestre) y eso puede tener importancia para las primeras estrategias de conservación de esta especie en esos países sudamericanos.

\section{Amplificación de ADN fecal}

De las 25 muestras de heces analizadas recolectadas en el Parque Nacional Sajama, únicamente cinco mostraron pertenecer a pumas diferentes. Esta es una proporción menor a la determinada por Miotto et al. (2007) para 20 muestras de heces recolectadas en la Estación Ecológica de Jataí y en el parque estatal Vassununga en el estado brasileño de São Paulo. Estos autores determinaron un número mínimo de nueve pumas en la región mencionada en un área mucho más pequeña a la aquí estudiada en los Andes bolivianos. Resulta extremadamente importante poder utilizar heces como un medio de obtención de ADN ya que los felinos, en general, poseen densidades poblacionales bajas, son elusivos y su captura implica un riesgo para ellos y para los humanos que participan en la misma (Wayne \& Morin 2004). Además, las heces son un registro abundante y unos pocos gramos contienen ADN de miles de células de la mucosa intestinal (Albaugh et al. 1992). Miotto et al. (2007) mostraron un éxito de amplificación mayor al obtenido en el presente trabajo (60 versus $40 \%$ ) pero, curiosamente, ellos lograron amplificar únicamente cuatro de los nueve microsatélites que emplearon, mientras que en nuestro caso amplificamos los siete microsatélites ensayados. Ernest et al. (2000) obtuvieron un éxito de amplificación similar al nuestro. Estos autores recolectaron 32 excrementos del Valle de Yosemite, de los que amplificaron $15(47 \%), 12$ perteneciendo a nueve pumas diferentes (tres excrementos pertenecieron a un mismo puma) y tres perteneciendo a lince (Lynx rufus Schreber, 1777).

Consideraciones genéticas del puma del altiplano boliviano: alta variabilidad genética y elevado flujo génico con las poblaciones analizadas en diversos países sudamericanos

La primera consideración remarcable es la elevada diversidad genética encontrada en la pequeña muestra analizada de pumas del altiplano boliviano $(\mathrm{H}=0,94) \mathrm{y}$, en general, para la muestra global de pumas estudiados en Colombia, Perú, Ecuador, Venezuela y la Amazonía occidental brasileña $(H=0,85)$. Como primera aproximación, estos valores resultaron superiores al valor reportado inicialmente por Menotti-Raymond \& O'Brien (1995) $(H=0,61)$ para el puma a través de todo el rango de distribución de la especie. Efectivamente, las poblaciones sudamericanas de puma han mostrado niveles de diversidad genética más elevadas que las poblaciones norteamericanas (Culver et al. 2000). De hecho, los pumas norteamericanos mostraron un $50 \%$ menos de alelos que los pumas sudamericanos para los microsatélites comunes analizados por Culver et al. (2000) y Ernest et al. (2003). Incluso, los pumas californianos mostraron un $73 \%$ menos de alelos que los pumas sudamericanos, ratificando los elevados niveles de variabilidad genética encontrados en los pumas bolivianos. A modo de ejemplo, 
comparemos el valor, $\mathrm{H}=0,94$, obtenido en tan solo ocho pumas bolivianos respecto a los valores encontrados para dos poblaciones de pumas en Texas (Walker et al. 2000). Para la población del sur de Texas, la diversidad genética fue extremadamente baja $(\mathrm{H}=0,29)$ mientras que para la población del oeste de Texas, la estimación fue más elevada pero claramente inferior para la reportada en Bolivia $(H=0,47)$. De hecho, Culver et al. (2000) determinaron una $\mathrm{H}$ promedio para los pumas sudamericanos de 0,71 frente a $\mathrm{H}=0,42$ para los norteamericanos (11,1 frente a 6,4 para el número promedio de alelos, respectivamente). De los cuatro acervos genéticos detectados en Sudamérica por esos autores, el que corresponde al rango geográfico estudiado aquí, presentó la $\mathrm{H}$ más elevada $(0,75)$, aunque inferior al valor reportado por nosotros en el presente estudio, mientras que los otros tres acervos detectados en Sudamérica presentaron valores de $0,74,0,71$ y 0,64 , respectivamente. También este acervo mostró el mayor número de alelos (91) frente a los 86, 67 y 60 de los otros tres acervos sudamericanos detectados. También, este acervo presentó, junto a otro, el mayor número de alelos únicos (cinco), mientras que los dos acervos genéticos sudamericanos restantes solo presentaron un alelo privado.

Si comparamos los alelos detectados en el presente trabajo, tanto para los pumas bolivianos, como para los pumas de los otros países sudamericanos, respecto a los encontrados en los pumas californianos, las diferencias en el número de los mismos es evidente. Una comparación entre los cinco microsatélites analizados simultáneamente en

TABLA 5

Determinación del estadístico $\theta\left(=4 \mathrm{~N}_{\mathrm{e}} \mu\right.$; siendo $\mathrm{N}_{\mathrm{e}}$ el numero efectivo y $\mathrm{m}$ la tasa de mutación por generación) en la muestra de pumas bolivianos y en la muestra de pumas de otras áreas del noroccidente de Sudamérica en Colombia, Perú, Ecuador, Venezuela y fracción occidental de la

Amazonía brasileña. El estadístico $\theta$ fue calculado con el método de los momentos $\left(\theta_{\mathrm{o}}\right)$ y con el método de máxima verosimilitud de Nielsen (1997) $(\theta)$

Determination of the $\theta\left(=4 \mathrm{~N}_{\mathrm{e}} \mu\right.$; being $\mathrm{N}_{\mathrm{e}}$ the effective number and $\mathrm{m}$ the mutation rate per generation $)$ statistic in the Bolivian puma sample and in the puma sample from other north-western South American areas in Colombia, Perú, Ecuador, Venezuela and western Brazilian Amazon. The $\theta$ statistic was calculated with the moment method $\left(\theta_{0}\right)$ and with the Nielsen's (1997) maximum likelihood procedure $(\theta)$

\begin{tabular}{|c|c|c|c|}
\hline \multirow[b]{2}{*}{ Marcadores } & \multicolumn{3}{|c|}{ Pumas de altiplano boliviano } \\
\hline & $\theta_{\mathrm{o}}$ & $\theta$ & Log verosimilitud \\
\hline Fca 96 & 16,264 & 15,6131 & $-15,8136$ \\
\hline Fca 126 & 22,000 & 35,7500 & $-6,3583$ \\
\hline Fca 45 & 3,264 & 4,9935 & $-8,6866$ \\
\hline Fca 43 & 22,000 & 35,7500 & $-6,4211$ \\
\hline Fca 08 & 100,500 & 125,1225 & $-8,7688$ \\
\hline Fca 391 & 3,167 & 6,3491 & $-3,6822$ \\
\hline \multirow[t]{3}{*}{ Fca 24} & 21,833 & 49,9983 & $-6,0372$ \\
\hline & $27,004 \pm 33,48$ & $39,082 \pm 4,49$ & \\
\hline & \multicolumn{3}{|c|}{ Puma del resto del área de estudio } \\
\hline Fca 96 & 38,262 & 44,0014 & $-49,3882$ \\
\hline Fca 126 & 8,017 & 24,4532 & $-19,4534$ \\
\hline Fca 45 & 1,816 & 4,6449 & $-14,5900$ \\
\hline Fca 43 & 18,998 & 21,8973 & $-23,4099$ \\
\hline Fca 08 & 50,410 & 72,3384 & $-45,4438$ \\
\hline Fca 391 & 51,372 & 59,0781 & $-48,7647$ \\
\hline \multirow[t]{2}{*}{ Fca 24} & 36,437 & 52,2874 & $-26,0624$ \\
\hline & $29,33 \pm 19,91$ & $39,814 \pm 23,79$ & \\
\hline
\end{tabular}


ambos estudios es la siguiente: Para Fca 96, una primera muestra estudiada por Ernest et al. (2000) $(\mathrm{n}=52)$ reveló cuatro alelos $(191,201$, 205, $209 \mathrm{pb}$ ), mientras que una muestra de 410 pumas estudiada posteriormente por los mismos autores (Ernest et al. 2003) detectó un alelo más a los determinados en el primer estudio (203 pb). En la muestra boliviana, de tan solo ocho animales, se detectaron siete alelos y en la de 45 animales de otros países del entorno se determinaron 15 alelos diferentes. Todos los alelos detectados en California estuvieron presentes en la muestra latinoamericana y dos de ellos en la boliviana (203 y 209 pb). Para Fca 126, se detectaron cuatro y seis alelos, respectivamente, en los dos estudios de Ernest et al. $(2000,2003)(131,135,137,139,141 \mathrm{y}$ $143 \mathrm{pb})$. Dos de esos alelos fueron encontrados en la muestra boliviana (135 y $141 \mathrm{pb})$ y todos ellos estuvieron incluidos dentro de los detectados para la muestra latinoamericana. Para Fca 45, únicamente se detectó un alelo de $127 \mathrm{pb}$ en las muestras de California, mientras que en las muestras de Bolivia y otros países latinoamericanos se determinaron cuatro y cinco alelos, respectivamente. Para Fca 43, en la primera muestra californiana se obtuvieron tres alelos $(124,134$ y $136 \mathrm{pb})$, mientras que en la segunda muestra se obtuvo un cuarto alelo adicional de $138 \mathrm{pb}$. En la muestra boliviana (tres alelos), se detectaron dos de esos alelos (124 y 138 pb) y en la muestra de otros países latinoamericanos, se determinaron 10 alelos, incluyendo todos los alelos detectados en California. Finalmente, para Fca 08, ambas muestras californianas detectaron dos alelos (152 y $164 \mathrm{pb}$ ). Ninguno de esos alelos fue encontrado en las muestras de Bolivia y de los restantes países latinoamericanos estudiados, aunque, en ambas, se encontraron un mayor número de alelos (tres y 12, respectivamente). Resulta claro, pues, que la riqueza genética de los pumas bolivianos, y de otros países de Latinoamérica, es superior a la de los pumas norteamericanos. Los resultados de los microsatélites son compatibles con los obtenidos mediante haplotipos de ADN mitocondrial (16S rRNA, ATPase-8, NADH-5) encontrados por Culver et al. (2000). Todos los pumas al norte de Guatemala poseen un único haplotipo mitocondrial $\mathrm{M}$ (con la excepción de cuatro ejemplares del noroeste pacífico de Norteamérica). Se encontraron tres haplotipos en Centroamérica ( $\mathrm{C}, \mathrm{F}, \mathrm{M})$ y 11 haplotipos en Sudamérica (A-B, D-L). Los haplotipos M y F se encuentran a través de toda Norte y Sudamérica. Los otros haplotipos están más restringidos geográficamente. Los dos haplotipos (H e I) con estados más ancestrales se encontraron en animales de Brasil y Paraguay. El haplotipo $\mathrm{F}$ fue compartido por animales de Venezuela, Brasil, Guayana, Ecuador, Perú, Bolivia, norte de Argentina y Costa Rica. Muchos de los ejemplares analizados en el presente estudio con microsatélites pertenecen, precisamente, a ese rango de distribución donde ese haplotipo mitocondrial es el dominante, lo cual ratifica la poca diferenciación genética encontrada entre los pumas del presente estudio por tener todos ellos un origen genético común. Culver et al. (2000) definieron a este grupo del norte y occidente de Sudamérica (donde geográficamente están enclavados los 53 pumas aquí analizados) como Puma concolor concolor. De hecho, la diversidad nucleotídica mitocondrial (p) de este grupo fue la menor $(0,0004)$ de los cuatro grupos sudamericanos detectados por ellos, mostrando un único origen genético. Por lo tanto, existe plena consistencia entre los resultados mitocondriales de Culver et al. (2000) y los resultados aquí mostrados con siete microsatélites de ADN nuclear.

La estructura reproductiva de la especie probablemente facilita los elevados niveles de diversidad genética encontrada en las poblaciones del presente estudio. Los pumas son polígamos y un animal puede reproducirse año tras año si presenta estabilidad en su rango territorial (Seidensticker et al. 1973). Además, las hembras pueden entrar en estro en cualquier época del año, aunque los felinos en general sean estacionales, lo que favorece la dispersión de características genéticas. Igualmente, la hembra puede entrar en estro en pocos días si la camada fallece a las pocas horas de nacer (Eaton \& Verlander 1977) lo que aumenta el potencial reproductivo de la especie y sus potenciales números efectivos. Adicionalmente, los individuos alcanzan la madurez sexual en relativamente poco tiempo. Por ejemplo, las hembras alcanzan esa madurez hacia los 2 o 3 años de vida (Eaton \& Verlander 1977). Young \& Goldman (1946) calcularon una vida promedio en la naturaleza de 7,5 años, mientras que Spector (1956), calculó un promedio de 9 
años. Esa longevidad favorece que el número de crías nacida por hembra sea importante y eso aumenta la posibilidad de un flujo génico elevado, al incrementarse potencialmente los números efectivos. Recuérdese que el flujo génico $\left(\mathrm{N}_{\mathrm{e}} \mu\right)$ es una función del número efectivo de las poblaciones. Además, diversos trabajos han demostrado que el flujo génico es la principal causa de aumento de la variabilidad genética en poblaciones previamente desconectadas (Slatkin 1977, Ruiz-García 1991). Los pumas exhiben un alto grado de tolerancia con otros miembros de la especie aunque no muestren un comportamiento social. Hornocker (1969) no encontró defensa territorial activa con pumas transeúntes de ambos sexos moviéndose libremente a través de territorios ocupados. De hecho, este mismo autor sugirió que el estatus reproductivo de la hembra y la edad y número de crías determina su rango estacional de movimiento en Idaho (USA). También los pumas poseen una gran capacidad de superar obstáculos geográficos. Ernest et al. (2003) encontraron que ríos grandes en el occidente de la Sierra Nevada de California y grandes autopistas no fragmentan genéticamente las poblaciones de puma de esa zona. Aunque estos autores encontraron heterogeneidad genética significativa entre los pumas del Parque Nacional Yosemite en la ladera occidental de la Sierra Nevada y el Valle Round en la ladera oriental de esta sierra $\left(\mathrm{F}_{\mathrm{ST}}=\right.$ $0,07)$, otros autores han determinado una fuerte capacidad migratoria del puma cruzando esa zona. Algunos animales migran periódicamente durante la primavera y regresan en otoño (Pierce et al. 1999). Desde el Valle Round se han observado pumas que han emigrado en todas direcciones. Por ejemplo, se detectó una hembra que migró $170 \mathrm{~km}$ al norte y dos machos que se dispersaron $120 \mathrm{~km}$ al este $\mathrm{y}$ $200 \mathrm{~km}$ al sureste, respectivamente. De hecho, los machos juveniles se dispersan con más probabilidad que las hembras a larga distancia desde su rango natal, lo cual favorece el flujo génico. En general, los pumas necesitan territorios mayores a los $100 \mathrm{~km}^{2}$ (Sweanor et al. 2000) y pueden llegar a dispersarse incluso en zonas de fuerte discontinuidad de hábitat (Ruth et al. 1998), llegando los eventos de dispersión registrados hasta los $450 \mathrm{~km}$ por parte de machos subadultos (Anderson et al. 2004). Incluso, en el divagar nocturno buscando presas pueden recorrer, en promedio, $9 \mathrm{~km}$. Todo ello, potencialmente, ayuda a la dispersión de los genes y a unos elevados niveles de diversidad genética. Desde la perspectiva de la biología de la conservación es muy importante determinar esos niveles de diversidad genética. Niveles bajos de este concepto denotan posible desaparición de flujo génico entre poblaciones, disminución del potencial evolutivo de una población frente a cambios ambientales y, consecuentemente, incremento del riesgo de extinción (Lande \& Barrowclough 1987), incluyendo disminución de la capacidad reproductiva (Wildt et al. 1987) y de la capacidad inmunitaria (Carpenter et al. 1996), debido a tamaños poblacionales pequeños. Aparentemente, la pequeña muestra de pumas analizada procedente del altiplano boliviano no parece mostrar síntomas de esa naturaleza. Los elevados niveles encontrados de variabilidad genética entre los pumas bolivianos y los de otras áreas de Latinoamericana muestran indirectamente que el flujo génico histórico entre ellas ha sido importante, lo cual se corrobora con la escasa heterogeneidad genética encontrada y el bajo potencial de asignación correcta de los pumas bolivianos. Ernest et al. (2003) mostraron que los pumas que habitan las regiones costeras de California (con grandes ciudades y obstáculos) presentaron menor heterocigosis que las poblaciones del interior de ese estado. Claramente, la mayor fragmentación y destrucción del territorio en la zona costera disminuye la posibilidad de flujo génico y eso se traduce en una menor variabilidad genética en las poblaciones de puma de esa zona, además de la disminución de los números efectivos, lo cual incrementa los efectos homogenizantes de la deriva genética y de la endogamia.

La elevada capacidad de dispersión de los pumas se observa también en la distribución de las secuencias del gen FIV-Pco del lentivirus felino de la inmunodeficiencia (FIV) (Carpenter et al. 1996). Estas secuencias mostraron una gran diversidad, mayor que la determinada en los gatos domésticos o en los leones. En este sentido, los autores referidos indican la sorprendente cantidad de diversidad en las secuencias de Wyoming, ya que todas ellas provienen de un área relativamente pequeña del Parque Nacional Yellowstone. 
Esto puede estar motivado porque desde 19201970 , los pumas fueron eliminados de ese parque. Posteriormente, y de forma natural, el área fue recolonizada por animales procedentes de otras zonas con diferentes tipos de FIV. Los eventos de extinción-recolonización (Slatkin 1977, Wade \& McCauley 1988) pueden aumentar considerablemente la variabilidad genética dentro de las poblaciones.

¿Existen diferentes subespecies de puma en el área geográfica analizada?

Dependiendo de los autores, en el área analizada de Bolivia, junto con las zonas estudiadas en Colombia, Perú, Ecuador, Venezuela y Amazonía occidental brasileña, han sido determinadas diversas subespecies de puma. Por ejemplo, Weigel (1959) citó cinco posibles subespecies en el área geográfica abarcada en nuestros análisis genéticos. Estas serían Puma concolor bangsi (en los Andes de Colombia, Ecuador y Perú; localidad tipo: Dibulla, Magdalena, Colombia), P. c. osgoodi (en la zona centro-oriental de Bolivia; localidad tipo: Buena Vista, Santa Cruz, Bolivia), P. c. discolor (en la zona oeste y sur de Venezuela, Guyana y norte de la Amazonía brasileña), P.c. concolor (en la zona occidental de la Amazonía brasileña), y $P$. c . acrocodia (en Paraguay y zona del chaco boliviano; localidad tipo: Descalvados, Mato Grosso, Brasil). Para Young \& Goldman (1946), en la extensión geográfica estudiada, se encontrarían P. c. bangsi (en la zona norte de Colombia y zona norte occidental de Venezuela), P. c. soderstromi (zona andina y chocoana de Colombia y Ecuador; localidad tipo: Nono, Monte Pichincha, Ecuador), P. c. incarum (zona andina peruana; localidad tipo: Piscocucho. Cuzco, Perú), P. c. osgoodi (en la zona central de Bolivia), $P$. c . acrocodia (mismo caso anterior), P. c. anthonyi (Llanos venezolanos y colombianos; localidad tipo: Monte Duida, Amazonas venezolano), P. $c$. concolor (en la mitad oriental de Venezuela, Guyanas y Surinam) y $P$. c. borbensis (en buena parte de la Amazonía brasileña; localidad tipo: Borba, Río Madeira-Amazonas, Brasil). Cabrera (1957) mostró una disposición subespecífica diferente para el área considerada: P. c. bangsi (Andes colombianos y ecuatorianos), P. c. incarum (Andes peruanos y bolivianos), $P$. c . osgoodi (zona selvática boliviana), $P$. c c borbensis (Amazonía colombiana, peruana y buena parte de la Amazonía occidental brasileña), $P$. c . anthonyi (parte más al este de los llanos orientales colombianos, llanos venezolanos y sur de Venezuela) y P. c. concolor (en la parte más oriental de Venezuela, Guyanas, Surinam y parte brasileña de la desembocadura del Amazonas). Hershkovitz (1959) agrupó las susbespecies $P$. c. borbensis, P. c. anthonyi y $P$. c. concolor en una sola subespecie, $P$. $c$. discolor. Sin embargo, los resultados moleculares obtenidos con siete microsatélites muestran que los pumas procedentes geográficamente de esas subespecies comentadas no se diferencian consistentemente (bajas estimas de heterogeneidad genética y precaria asignación poblacional a su lugar de origen), mientras que las estimas teóricas de flujo génico son elevadas (la mayoría de ellas entre tres y 22 animales por generación). Esto pone en evidencia, al menos, para los marcadores moleculares empleados, que el puma andino boliviano no se diferencia en gran medida de otras poblaciones de pumas de otros países andinos y amazónicos del entorno. Este es un resultado que pone en duda la validez taxonómica de las subespecies morfológicas citadas. De hecho, los estudios morfométricos han sido muy ambiguos en la descripción de subespecies de puma. Por ejemplo, Mazzolli \& Ryan (1997) mostraron que la localidad tipo para $P$. c . concolor ha cambiado tres veces desde su primera descripción. En la actualidad, la misma se extendería desde el noreste del Brasil, descendiendo por la costa Atlántica brasileña, hasta Uruguay, noreste de Argentina y este de Paraguay. Sin embargo, estos autores encontraron diferencias significativas entre 29 cráneos estudiados (15 machos y 14 hembras) de dos regiones (sur y sureste del Brasil) dentro del rango de distribución de $P$. c . concolor. Los machos de ambas poblaciones se diferenciaron significativamente en la longitud postorbital, anchura interorbital y zigomática y longitud de la mandíbula. Las hembras se diferenciaron por la anchura del rostro, la longitud basal y por la longitudes total, condilobasal y mandibular. En general, los pumas de la población sur tuvieron dimensiones craneales mayores, los machos con una anchura significativamente mayor y las hembras con una longitud, también, significativamente superior a lo reportado para 
los pumas de la población sureste. Ellos concluyeron con la existencia de bajos niveles de migración entre ambas poblaciones de pumas. Pero los estudios morfométricos, a diferencia de los moleculares, son dados a encontrar un gran número de subespecies por dos motivos no suficientemente ponderados por los autores. El primero es la utilización de muy pocos especímenes para definir subespecies diferentes (más peso de una visión tipológica que poblacional). Por ejemplo, Young \& Goldman (1946) utilizaron un solo cráneo para describir la subespecie P. c. greeni, y un macho y una hembra para describir $P . \quad c$. capricornensis. Sin embargo, Hershkovitz (1959) los tornó sinónimos a P. c. concolor en la costa este del Brasil. En segundo lugar, el taxón comentado de puma ( $P$. c . concolor) habita regiones semiáridas al igual que bosques atlánticos y sabanas. Las dos poblaciones comparadas por Mazzolli \& Ryan (1997) están separadas por unos $500 \mathrm{~km}$ de distancia y, aunque los autores comentan que no existen grandes diferencias de vegetación entre ambas zonas, las presiones selectivas ambientales pueden ser diferentes (e.g., recursos, presas) por lo que la variabilidad morfométrica puede resultar más bien de presiones selectivas diferentes que de la inexistencia de un contacto genético entre las poblaciones. En este sentido sería bueno agregar que los resultados obtenidos con este tipo de estudios con marcadores neutros como los microsatélites exhiben resultados que dan cuenta de sucesos históricos demográficos pero no de eventos de selección.

El ejemplo descrito por Iriarte et al. (1990) es muy explicativo en este sentido. Estos autores encontraron que el peso medio de los vertebrados depredados por los pumas estaba positivamente correlacionado $(r=0,875)$ con el peso promedio de los pumas. El peso medio de las presas vertebradas de los pumas fue menor en áreas cercanas al Ecuador y mayor en las áreas más alejadas de este. Por ejemplo, en Norteamérica, el $68 \%$ de las presas son ungulados, especialmente ciervos. Por el contrario, en Centro y Sudamérica, los ungulados solamente alcanzan el $35 \%$ de las presas del puma. Esto significa que el tamaño y la disponibilidad de las presas ejerce una importante presión selectiva en el tamaño de los pumas y, por lo tanto, en las variables morfométricas. Igualmente, la competencia con el jaguar (Panthera onca Linnaeus, 1758) podría ser un factor selectivo importante que potenciara diferencias morfológicas (menor tamaño) en aquellos pumas que viven en simpatría con el gran felino manchado.

Los marcadores moleculares microsatélites utilizados en este estudio, contrariamente, al poseer una dinámica básicamente neutral, reflejan mucho mejor la conexión genética entre las poblaciones. La inexistencia de subespecies de pumas en los países analizados (Bolivia, Colombia, Perú, Ecuador, Venezuela y Amazonía occidental brasileña) mediante microsatélites se ve ratificada con los resultados de Culver et al. (2000). Estos autores determinaron, a partir de 315 pumas analizados a través de toda su extensión geográfica, la existencia de seis grupos filogeográficos (o subespecies) frente a las 32 subespecies morfológicamente descritas (Young \& Goldman 1946). De hecho, la población norteamericana, en la que se habían determinado 15 subespecies, resultó genéticamente homogénea respecto a lo encontrado en Centro y Sudamérica. Estos autores muestran que la uniformidad de ADN mitocondrial y la reducida variabilidad de microsatélites encontrada en la población norteamericana es compatible con un origen reciente (Pleistoceno, hace 10.000 años), donde hubo reemplazamiento y recolonización de la población original norteamericana por un número reducido de fundadores procedentes de Sudamérica. Cuatro de los seis grupos genéticos encontrados por Culver et al. (2000) reflejan regiones geográficas bien definidas, mientras que los otros dos forman zonas híbridas de subespecies geográficamente subyacentes. Como se comentó, anteriormente, el grupo genéticamente bien diferenciado del noroccidente de Sudamérica, en el que están incluidos nuestros individuos analizados, es el denominado $P$. concolor concolor. Fue el que presentó mayor diversidad genética, mayor número de alelos y mayor número de alelos privados para los microsatélites estudiados, junto con el grupo detectado en centro, sur y costa Atlántica brasileña ( $P$. concolor capricorniensis), de los seis grupos genéticamente diferenciados por Culver et al. (2000). Una amplia distribución continua de alelos fue observada entre esos dos acervos, 
con una $\mathrm{F}_{\mathrm{ST}}(=0,031)$ significativa, pero siendo la más pequeña entre todos los pares de los seis acervos genéticos comparados, mientras que los otros acervos poseían subconjuntos de alelos detectados en esas dos agrupaciones y valores de $\mathrm{F}_{\mathrm{ST}}$ que alcanzaron hasta 0,37 . Eso significa que ambos acervos pueden estar en el origen de los otros acervos genéticos de pumas detectados en toda América. Los árboles neighborg-joining, con dos distancias genéticas diferentes (coeficiente de parentesco y proporción de alelos compartidos), muestran cómo los ejemplares clasificados como concolor, soderstromi, incarum, bangsi y osgoodi formaron un grupo sólido y fuertemente homogéneo. Nuestros resultados con siete microsatélites ratifican la inexistencia de subespecies en el rango geográfico analizado y muestran como la forma andina boliviana no se diferencia genéticamente de ese grupo de pumas que encontramos en Perú, Ecuador, Colombia, Venezuela y parte de la Amazonía occidental brasileña a pesar que algunos autores clasificaron a los pumas bolivianos como pertenecientes a diferentes subespecies (P. c. incarum y P. c. osgoodi).

Sin embargo, eso no significa que en otras regiones donde habita el puma no pueda existir una mayor divergencia genética entre las poblaciones de esta especie debido a la incidencia humana, o a la existencia de conspicuas barreras geográficas. Este es el caso del puma en California. Ernest et al. (2003) encontraron una fuerte subdivisión genética asociada a barreras geográficas y al aislamiento por distancia (las distancias geográficas entre unidades regionales explicaron el $56 \%$ de las diferencias genéticas encontradas entre los pumas de esas unidades). La bahía de San Francisco, el delta del río San Joaquín y Sacramento, el valle central y Los Ángeles se constituyeron como poderosas barreras geográficas ya que las poblaciones de pumas a un lado y otro de las mismas presentaron frecuencias alélicas substancialmente diferentes. Por el contrario, el transecto nortesur a lo largo de la zona occidental de la Sierra Nevada de California mostró unos niveles de flujo génico substancialmente elevados. Estos autores demostraron mediante el uso del programa STRUCTURE la existencia de dos acervos genéticos bien diferenciados respecto a los pumas del resto de California. En uno de ellos se asoció el $82 \%$ de los individuos de la costa norte de California y en el otro el $87 \%$ de los individuos del suroeste de California. Esto es, en ciertas áreas de la distribución de su rango, las poblaciones de pumas parecen seguir una estructura metapoblacional (Beier 1996, Sweanor et al. 2000), pero en otras zonas los animales muestran desplazamientos extremadamente largos (Pierce et al. 1999) o rápidas expansiones poblacionales (Riley \& Malecki 2001), lo que, indudablemente, facilita un elevado flujo génico. Esta dicotomía es visible en diversos estudios. Walker et al. (2000) encontraron una elevada diferenciación genética entre las poblaciones de pumas del sur y oeste de Texas. Estos autores estimaron valores de $F_{\text {ST }}$ oscilando entre 0,011 y 0,30 para los siete microsatélites polimórficos que emplearon, con un promedio de 0,107 . Para el estadístico $\mathrm{R}_{\mathrm{ST}}$ determinaron valores que oscilaron entre 0 y 0,465 , con un promedio de 0,286 . Contrariamente a esos resultados, Sinclair et al. (2001) no encontraron diferenciación genética entre 10 poblaciones de pumas en Utah, por lo que se infiere que el flujo génico es muy elevado en esa zona geográfica de Norteamérica. Este parece ser el caso para el área geográfica de Sudamérica aquí estudiada, ya que los estadísticos de heterogeneidad genética resultaron ostensiblemente menores que los referidos para las poblaciones de Texas o California de pumas $\left(\mathrm{F}_{\mathrm{ST}}=0,011 ; \mathrm{G}_{\mathrm{ST}}=0 ; \mathrm{R}_{\mathrm{ST}}=0,05-0,07\right)$.

Obviamente, las estimas de flujo génico entre la muestra boliviana y las de otros países del entorno fueron ostensiblemente superiores (para $\mathrm{F}_{\mathrm{ST}}, \mathrm{Nm}=6-22$; para $\mathrm{R}_{\mathrm{ST}}, \mathrm{Nm}=3-5$; para alelos privados, $\mathrm{Nm}=1,29)$ a las reportadas para las poblaciones de Texas $\left(\right.$ para $\mathrm{F}_{\mathrm{ST}}, \mathrm{Nm}=$ 2,07; para $\mathrm{R}_{\mathrm{ST}}, \mathrm{Nm}=0,625$; para alelos privados, $\mathrm{Nm}=0,545)$. Estas estimas están basadas en la asunción de un modelo WrightFisher con equilibrio deriva-flujo génico (no para el procedimiento de los alelos privados) que probablemente no se da para las poblaciones de pumas estudiadas, lo que podría ofrecer estimas de flujo génico no concordantes con la realidad. Sin embargo, Slatkin \& Barton (1989) mostraron lo extraordinariamente robustas que son estas estimas de flujo génico a pesar de las violaciones que en el mundo real se pueden dar de ese modelo. Únicamente Fca 96 presentó heterogeneidad genética entre la 
muestra boliviana y la otra agrupación geográfica. Por el contrario, entre las dos poblaciones de Texas, mucho más próximas entre sí, cuatro microsatélites resultaron significativamente heterogéneos (Fca 77, 78, 90, 96). La diferenciación en cuanto a los resultados de asignación poblacional entre ambos casos es notable. Mientras que los animales bolivianos resultaron en muchos análisis indistinguibles del otro grupo geográfico, los animales de Texas quedaron bastante bien asignados a cada una de las dos poblaciones referidas (88 \%). Únicamente un ejemplar del sur de Texas quedó asignado a la población del oeste $(6 \%)$ y dos animales del oeste de Texas quedaron asignados en la población de Sur.

El presente trabajo pone de manifiesto cómo los resultados genéticos poblacionales, haciendo uso de marcadores moleculares, posibilitan la obtención de información importante de ciertos aspectos demográficos e históricos de especies de interés biológico, a partir de muestras no invasivas. Se mostró, también, que el puma que habita los Andes bolivianos no se diferencia genéticamente de los pumas que habitan la región noroccidental de Sudamérica a pesar de que algunos autores los habían clasificado como pertenecientes a subespecies diferentes a partir de estudios morfométricos. Sin embargo, el número de pumas bolivianos estudiado es muy pequeño. Por ello, se debería ampliar el número de ejemplares bolivianos estudiado para determinar si, en el interior de ese país, existe heterogeneidad genética entre sus poblaciones de puma y qué consecuencias podría tener ese hallazgo para la conservación efectiva de este gran felino. Resulta trascendente determinar la posible existencia de heterogeneidad genética entre la población andina de pumas y aquellas que se encuentran en el entorno de los ríos Mamoré, Itéñez, Yata y Beni, en la Amazonía boliviana.

\section{AGRADECIMIENTOS}

Los autores agradecen profundamente la colaboración de la administración del PN Sajama (Bolivia) para este trabajo y especialmente al Cuerpo de Guardaparques por ayudar a recolectar las heces. El primer autor agradece a las personas y a las comunidades indígenas que le ayudaron a obtener muestras de pumas a través de Colombia (comunidades indígenas Jaguas, Ticunas, Huitoto, Tucano, Nonuya, Yuri y Yucuna), Perú (comunidades indígenas Bora, Ocaina, Shipigo-Comibo, Capanahua, Angoteros, Orejón, Cocama, Kishuarana y Alamas), y en la Amazonía occidental brasileña (Marubos, Matis, Mayoruna, Kanaimari, Kulina, Maku y Waimiri-Atroari). Se agradece la ayuda ofrecida por Armando Castellanos y Luis Albuja en la obtención de algunas de las muestras ecuatorianas y de Andrés Eloy Bracho en la obtención de muestras venezolanas. Este trabajo fue financiado por la Wildlife Conservation Society y por el Laboratorio de Genética de Poblaciones Molecular y Biología Evolutiva del Departamento de Biología de la Pontificia Universidad Javeriana en Bogotá (Colombia). Finalmente se agradece al Ministerio de Desarrollo Sostenible y Planificación, al Viceministerio de Medio Ambiente, Recursos Naturales y Desarrollo Forestal, a la Dirección General de Biodiversidad, a la Colección Boliviana de Fauna (Dra Julieta Vargas), y a CITES, todos ellos en Bolivia, al Ministerio de Medio Ambiente de Ecuador, y a PRODUCE, Dirección Nacional de Extracción y Procesamiento Pesquero, al Consejo Nacional del Ambiente y al Instituto Nacional de Recursos Naturales (INRENA) de Perú por los permisos de obtención y transporte de muestras de pumas de esos países.

\section{LITERATURA CITADA}

ANDERSON AE (1983) A critical review of literature on puma (Felis concolor). Special Report, Colorado Division of Wildlife, Wildlife Research Section, Denver, Colorado, USA. 99 pp.

ANDERSON CR, FG LINDZEY \& DB MCDONALD (2004) Genetic structure of cougar populations across the Wyoming basin: metapopulation or megapopulation. Journal of Mammaloy 85: 12071214.

ALBAUGH GP, V IYENGAR \& A LOHANI (1992) Isolation of exfoliated colonic epithelial cells, a novel, non-invasive approach to the study of cellular markers. International Journal Cancer 52: 347-350.

BADOUIN L \& P LEBRUN (2000) An operational Bayesian approach for the identification of sexually reproduced cross-fertilized populations using molecular markers. En: Dore C, Dosba F \& C Baril 
C (eds) Proceedings of the International Symposium on Molecular Markers for characterizing genotypes and identifying cultivars in Horticulture: 6-9. Montpellier, France.

BARTON NH \& M SLATKIN (1986) A quiasiequilibrium theory of the distribution of rare alleles in a subdivided population. Heredity 56: 409-416.

BEIER P (1993) Determining minimum habitat areas and habitat corridors for cougars. Conservation Biology 7: $94-108$.

BEIER P (1996) Metapopulation models, tenacious tracking, and cougar conservation. En: McCullough DR (ed) Metapopulations and wildlife conservation: 293-323. Island Press, Seattle, Washington, USA.

CABRERA A (1957) Catálogo de los mamíferos de América del Sur. Revista del Museo Argentino de Ciencias Naturales "Bernardino Rivadavia" (Argentina) 4: 290-295.

CARPENTER MA, EW BROWN, M CULVER, WE JOHNSON, J PECON-SLATTERY, D BROUSSET \& SJ O'BRIEN (1996) Genetic and phylogenetic divergence of feline immunodeficiency virus in the puma (Puma concolor). Journal of Virology 70 : 6682-6693

CAVALLI-SFORZA LL \& AWF EDWARDS (1967) Phylogenetic analysis: models and estimation procedures. Evolution 21: 550-570.

CHAKRABORTY R \& L JIN (1993) A unified approach to study hypervariable polymorphisms: Statistical considerations of determining relatedness and population distances. En: Pena SDJ, R Chakraborty, JT Epplen \& AJ Jeffreys (eds) DNA fingerprinting: state of the science: 153-175. Birkhauser, Basel, Switzerland.

CORNUET JM, S PIRY, G LUIKART, A ESTOUP \& M SOLIGNAC (1999) New methods employing multilocus genotypes to select or exclude populations as origins of individuals. Genetics 153: 1989-2000

CROW JF \& K AOKI (1984) Group selection for a polygenic behavioral trait: estimating the degree of population subdivision. Proceedings of National Academy of Sciences USA 81: 6073-6077.

CULVER M, WE JOHNSON, J PECON-SLATTERY \& SJ O'BRIEN (2000) Genomic ancestry of the American puma (Puma concolor). Journal of Heredity 91: 186-197.

CURIER MJP (1983) Felis concolor. Mammalian Species 200: 1-7.

EATON RL \& KA VELANDER (1977) Reproduction in the puma: biology, behavior and ontogeny. En: Eaton RL (ed) The world's cat: 45-70. Carnivore Research Institute, Burke Museum, University of Washington, Washington, Seattle, USA.

ERNEST HB, MCT PENEDO, BP MAY, M SYVANEN \& WM BOYCE (2000) Molecular tracking of mountain lions in the Yosemite valley region in California: genetic analysis using microsatellites and faecal DNA. Molecular Ecology 9: 433-441.

ERNEST HB, WM BOYCE, VC BLEICH, B MAY, SJ STIVER \& SG TORRES (2003) Genetic structure of mountain lion (Puma concolor) populations in California. Conservation Genetics 8: 353-366.

GOLDSTEIN DB, A RUIZ-LINARES, LL CAVALLISFORZA \& MW FELDMAN (1995) An evaluation for genetic distances for use with Microsatellite loci. Genetics 139: 463-471.

GOODMAN SJ (1997) $\mathrm{R}_{\mathrm{ST}}$ Calc: a collection of computer programs for calculating estimates of genetic differentiation from microsatellite data and determining their significances. Molecular Ecology 6: 881-885.

HERSHKOVITZ P (1959) Type locality of Felis concolor concolor Linnaeus. Proceeding of the Biological Society of Washington (USA) 72: 97-100.

HORNOCKER MG (1969) Winter territoriality in mountain lions. Journal of Wildlife Management 33: 457-464.

IRIARTE JA, WL FRANKLIN, WE JOHNSON \& KH REDFORD (1990) Biogeographic variation of food habits and body size of the America puma. Oecologia 85: 185-190.

KOEHLER GM \& MG HORNOCKER (1985) Mountain lions as a mortality factor in bobcats. En: Robertson J \& F Lindzey (eds) Proceedings of the second mountain lion workshop: 170-171. Utah Division of Wildlife Resources, Salt Lake City, Utah, USA.

LANDE R, GF BARROWCLOUGH (1987) Effective population size, genetic variation, and their use in population management. En: Soulé ME (ed) Viable populations for conservation: 87-123. Cambridge University Press, New York, New York, USA.

LANGELLA O (1999) Populations 1.2.30: a population genetic software. CNRS UPR9034. Disponible en: http://www.pge.cnrs-gif.fr/bioinfo/populations/ index.php.

LOGAN KA \& LL SWEANOR (2001) Desert puma: evolutionary ecology and conservation of an enduring carnivore. Island Press, Seattle, Washington, USA. 464 pp.

MENOTTI-RAYMOND MA, VA DAVID, LA LYONS, AA SCHAFFER, JF TOMLIN, MK HUTTON \& SJ O'BRIEN (1999) A genetic linkage map of microsatellites in the domestic cat (Felis catus). Genomics 57: 9-23.

MENOTTI-RAYMOND MA \& SJ O'BRIEN (1995) Evolutionary conservation of ten Microsatellite loci in four species of Felidae. Journal of Heredity 86: 319-322.

MIOTTO RA, FP RODRIGUES, G CIOCHETI \& PM GALETTI JR (2007) Determination of the minimum population size of pumas (Puma concolor) through fecal DNA analysis in two protected Cerrado areas in the Brazilian southeast. Biotropica 39: 647-654.

NEI M (1973) Analysis of gene diversity in subdivided populations. Proceedings of the National Academy of Sciences USA 70: 3321-3323.

NEI M (1978) Estimation of average heterozygosity and genetic distance from a small number of individuals. Genetics 89: 583-590.

NEI M, F TAJIMA \& Y TATENO (1983) Accuracy of estimated phylogenetic trees from molecular data. II. Gene frequency data. Journal of Molecular Evolution 19: 153-170.

NIELSEN R (1997) A likelihood approach to populations samples of microsatellite alleles. Genetics 146: 711-716

NOWELL K \& P JACKSON (1996) Wild cats. Status survey and conservation action plan, International Union for Conservation of Nature, Gland, Switzerland. $382 \mathrm{pp}$

PAETKAU D, W CALVERT, I STIRLING \& C STROBECK (1995) Microsatellite analysis of population structure in Canadian polar bears. Molecular Ecology 4: 347-354.

PATKEAU D, R SLADE, M BARDEN \& A ESTOUP (2004) Genetic assignment methods for the direct, real-time estimation of migration rate: a simulation- 
based exploration of accuracy and power. Molecular Ecology 13: 55-65.

PENROD K (2000) Missing linkages: restoring connectivity to the Californian landscape. San Diego Zoo, San Diego, California, USA. 117 pp.

PIERCE BM, VC BLEICH, JD WEHAUSEN \& RT BOWYER (1999) Migratory patterns of mountain lions: implications for social regulation and conservation. Journal of Mammalogy 80: 986-992.

PIRY S, A ALAPETITE, J M CORNUET, D PAETKAU, L BAUDOUIN \& A ESTOUP (2004) GENECLASS2: a software for genetic assignment and first-generation migrant detection. Journal of Heredity 95: 536-539.

RANNALA B \& JL MOUNTAIN (1997) Detecting immigration by using multilocus genotypes. Proceedings of the National Academy of Sciences USA 94: 9197-9201.

RAYMOND M \& F ROUSSET (1995) GENEPOP version 3.1 Population genetics software for exact tests and ecumenicism. Journal of Heredity 86: 248-249.

RILEY SJ \& RA MALECKI (2001) A landscape analysis of cougar distribution and abundance in Montana, USA. Environmental Management 28: 317-323.

ROELKE ME, JS MARTENSON \& SJ O'BRIEN (1993) The consequences of demographic reduction and genetic depletion in the endangered Florida panther. Current Biology 3: 340-350.

ROONEY AP, RL HONEYCUTT, SK DAVIS \& JN DERR (1999) Evaluating a putative bottleneck in a population of bowhead whales from patterns of microsatellite diversity and genetic disequilibria. Journal of Molecular Evolution 49: 682-690.

RUIZ-GARCÍA M (1993) Analysis of the evolution and genetic diversity within and between Balearic and Iberian cat populations. Journal of Heredity 84: 173-180.

RUIZ-GARCÍA M (1998) Genetic structure of different cat populations (Felis catus) in Spain, Italy and Argentina at a microgeographical level. Acta Theriologica 43: 39-64.

RUIZ-GARCÍA M \& D ALVAREZ (2000) Genetic microstructure in two Spanish cat populations I: Genic diversity, gene flow and selection. Genes and Genetic Systems 75: 269-280.

RUTH RK, LA LOGAN, LL SWEANOR, MG HORNOCKER \& LJ TEMPLE (1998) Evaluating cougar translocation in New Mexico. Journal of Wildlife Management 62: 1264-1275.

SAMBROOK J, EF FRITSCH \& T MANIATIS (1989) Molecular cloning: a laboratory manual. Cold Spring Harbor Laboratory Press, New York, New York, USA. 1325 pp.

SEIDENSTICKER JC, MG HORNOCKER, WV WILES \& JP MESSICK (1973) Mountain lion social organization in the Idaho primitive area. Wildlife Monographs 35: 1-60.

SINCLAIR EA, EL SWENSON, ML WOLFE, DC CHOATE, B BATES \& KA CRANDALL (2001) Gene flow estimates in Utah's cougars imply management beyond Utah. Animal Conservation 4: 257-264.

SLATKIN M (1977) Gene flow and genetic drift in a species subject to frequent local extinction. Theoretical Population Biology 12: 253-262.

SLATKIN M (1985) Rare alleles as indicators of gene flow. Evolution 39: 53-65.
SLATKIN M (1995) A measure of population subdivision based on microsatellite allele frequencies. Genetics 139: 457-462.

SPECTOR WS (1956) Handbook of biological data. W.B. Saunders Company, Philadelphia, Pennsylvania, USA. 584 pp.

SWEANOR LL, KA LOGAN \& MG HORNOCKER (2000) Cougar dispersal patterns, metapopulation dynamics and conservation. Conservation Biology 14: 798-808.

TABERLET P, S GRIFFIN, B GOOSSENS, S QUESTIAU, V MANCEAU, N ESCARAVAGE, L WAITS \& J BOUVET (1996) Reliable genotyping of samples with very low DNA quantities using PCR. Nucleic Acid Research 24: 3189-3194.

TABERLET P, L WAITS \& G LUIKHART (1999) No invasive genetic sampling: look before you leap. Trends in Ecology and Evolution 14: 323-327.

TAKAHATA N (1983) Gene identity and genetic differentiation of populations in the finite island model. Genetics 104: 497-512.

WADE MJ \& DE MCCAULEY (1988) Extinction and recolonization: their effects on the genetic differentiation of local populations. Evolution 42: 995-1005

WALKER CW, LA HARVESON, MT PITTMAN, ME TEWES \& RL HONEYCUTT (2000) Microsatellite variation in two populations of mountain lions (Puma concolor) in Texas. Southwestern Naturalist 45: 196-203.

WALSH PS, DA METZGER \& R HIGUCHI (1991) Chelex 100 as a medium for simple extraction of DNA for PCR-based typing from forensic material. BioTechniques 10: 506-513.

WAYNE RK \& PA MORIN (2004) Conservation genetics in the new molecular age. Ecological Environment 2: 89-97.

WEBB SD \& LG MARSHALL (1981) Historical biogeography of recent South America land mammals. En: Mares MA \& HH Genoways (eds) Mammalian biology in South America: 39-52. Pymatuning Laboratory of Ecology, University of Pittsburgh, Pittsburgh, Pennsylvania, USA.

WEBB SD \& A RANCY (1996) Late Cenozoic evolution of the Neotropical mammal fauna. En: Jackson JB, Budd AF \& AG Coates (eds) Evolution and environment in tropical America: 335-358. University of Chicago Press, Chicago, Illinois, USA.

WEBER JL \& C WONG (1993) Mutation of human short tandem repeats. Human Molecular Genetics 2: 1123-1128.

WEIGEL I (1959) Das Fellmuster der wildlebenden Katzenarten und der Hauskatze in vergleichender und stammesgeschichtlicher hinsicht. Saugetierkundlichen Mitteilungen 4: 1-119.

WILDT DE, KL BUSH, KL GOODROWE, C PACKER, AE PUSEY, JL BROWN, P JOSLIN \& SJ O'BRIEN (1987) Reproductive and genetic consequences of founding isolated lion populations. Nature 329: 328-331.

WRIGHT S (1951) The genetical structure of populations. Annals of Eugenics 15: 323-354.

YOUNG SP \& EA GOLDMAN (1946) The puma: mysterious American cat. American Wildlife Institute, Seattle, Washington, USA. 358 pp. 
